

\title{
Versatile Analytical Approach for Assessing Harmonic Distortion in Current-Driven Electrodynamic Loudspeakers
}

Etienne Gaviot, Mehran Erza, Frédéric Polet, Lionel Camberlein, Bruno Bêche

\section{- To cite this version:}

Etienne Gaviot, Mehran Erza, Frédéric Polet, Lionel Camberlein, Bruno Bêche. Versatile Analytical Approach for Assessing Harmonic Distortion in Current-Driven Electrodynamic Loudspeakers. J. Audio Eng. Soc., 2014, 62 (3), pp.127-144. 10.17743/jaes.2014.0011 . hal-00967321

\section{HAL Id: hal-00967321 https://hal.science/hal-00967321}

Submitted on 1 Apr 2014

HAL is a multi-disciplinary open access archive for the deposit and dissemination of scientific research documents, whether they are published or not. The documents may come from teaching and research institutions in France or abroad, or from public or private research centers.
L'archive ouverte pluridisciplinaire HAL, est destinée au dépôt et à la diffusion de documents scientifiques de niveau recherche, publiés ou non, émanant des établissements d'enseignement et de recherche français ou étrangers, des laboratoires publics ou privés. 


\title{
Versatile Analytic Approach to Assessing Harmonic Distortion in Current Driven Electrodynamic Loudspeakers
}

\author{
E. Gaviot ${ }^{1}$, M. Erza ${ }^{1}$, F. Polet ${ }^{1}$, L. Camberlein ${ }^{1}$, B. Bêche ${ }^{2,3}$ \\ ${ }^{1}$ Laboratoire d'Acoustique de l'Université du Maine, Micro_Cap_Ouest, LAUM, UMR CNRS 6613, Le Mans France \\ ${ }^{2}$ Institut de Physique de Rennes, IPR, UMR CNRS 6251, Rennes, France \\ ${ }^{3}$ Institut Universitaire de France (IUF), 103 bd Saint-Michel, 75005 Paris, France
}

\section{Abstract}

Current-controlling loudspeakers has been investigated since a significant time and is known as quite appreciated by demanding audiophiles. Today's new market research clearly moves to investigate on adequate innovative designs together with simple theoretical solutions to deal with their residual non-linear properties. Hence, this paper aims to present a compact analytical approach allowing to synthesize the harmonic distortion hindering the audio quality of electrodynamic loudspeakers, while considering separately the influence of the changes of their main constitutive parameters. As a great convenience the relevant compact way to shape Taylor polynomials provides simple expressions describing the first five harmonic distortion lines on the whole spectrum: Proceeding so clearly highlights the critical influence of each given parameter. Besides consistency when compared with numerical analysis operated with the Simulink $^{\circledR}$ software, this approach may be easily implemented with a standard spreadsheet application. We also highlight the interest to refer the acceleration of the diaphragm to that of the gravity reference level.

\section{O INTRODUCTION}

Sound processing with current driven loudspeakers depends critically on high quality transducers together with their relevant and adequate circuitry. Although nowadays this approach is far from being spread in today's audio industry, the development of high-quality miniaturized devices based on new materials is bound to start a significant change towards current drive policy. Moreover, besides cogent technical developments, strong simplifications regarding classical analytical approaches are most welcome to foster the mandatory engineering work enabling to reach production stage.

The main purpose of this paper is to present a compact and articulate analytical model of current driven loudspeakers so as to assess their remaining non-linear shortcomings. Displacement, speed and acceleration (quantity directly associated with the resulting sound pressure) of the voice coil can be easily characterized up to their first fifth-order harmonic distortion components along the whole spectrum. To cover the latter, numerical simulations require numerous calculations to deal with a specific isolated flaw. On the other hand, any $\mathrm{i}^{\text {th }}$-order harmonic distortion line $\left(\mathbf{H D}_{\mathbf{i}}\right)$ is classically referred to by way of plotting its respective acceleration level as a logarithmic ratio with that of the fundamental level. Conversely, we highlight in this paper the interest to depict each component together with the fundamental as a logarithmic ratio with the gravity acceleration level, allowing the observer to assess at a glance the spectral pattern of any $\mathrm{i}^{\text {th }}$-order harmonic distortion.

Straightforward models for coupling loudspeakers with electronics software are quite simple since based on RLC circuits [1]. Yet, despite picturing the impedance versus frequency relationship, such models are obviously unable to allow for the numerous shortcomings of loudspeakers, especially their nonlinear limitations. Indeed, nonlinear behaviours are out of reach of such models since neither electromechanical properties nor physical quantities, such as displacement, velocity, acceleration and force may be accurately accounted for. Since a long time, current drive of loudspeakers proved a well established way to reduce non linear distortion. However, despite numerous works and a significantly probing literature [2,3], quite few devices are nowadays available on the market. 
As a matter of fact the following fundamental mechanical and electrical equations describing a generic transducer can be written as $[3,4,6]$ :

$$
\begin{aligned}
& B_{l} \cdot i+\frac{1}{2} \cdot i^{2} \cdot \frac{d L_{e}}{d x}=M_{m} \cdot \frac{d^{2} x}{d t^{2}}+f_{m} \cdot \frac{d x}{d t}+k_{m} \cdot x \\
& e_{(t)}=R_{e} \cdot i_{(t)}+L_{e} \cdot \frac{d i}{d t}+B_{l} \cdot \frac{d x}{d t}
\end{aligned}
$$

As regards Eq.1, $\boldsymbol{x}$ is the displacement of the voice coil (m), $\mathbf{B}_{1}$ the force factor (T.m) of the motor system, $\boldsymbol{i}$ the driving current, $\boldsymbol{M}_{\mathrm{m}}$, the equivalent mass of the moving voice coil $[\mathrm{kg}], \boldsymbol{f}_{\mathrm{m}}$ the mechanical damping parameter and drag force $\left[\mathrm{N} . \mathrm{s} . \mathrm{m}^{-1}\right], \boldsymbol{k}_{\mathrm{m}}$ the suspension stiffness $\left[\mathrm{N} . \mathrm{m}^{-1}\right]$, and $\boldsymbol{L}_{\mathrm{e}}$ the voice coil inductance. The left member includes the useful drive force due to the Lorentz interaction, acting together with an extraneous component, the solenoid force (also referred to as the reluctance force), stemming from the stocked energy within the moving coil $[3,4,5,6]$.

Considering Eq.2, $\boldsymbol{R}_{\mathrm{e}}$ is the voice coil electrical resistance [ $\Omega$ ], and $\boldsymbol{e}$ the fem [V] observed at the transducer terminals during operation. Although valuable to assess the electrical behaviour of the system, Eq.2 becomes factually useless in the advantageous case of a current-drive policy since the designer has only to optimize the left member of Eq.1 so as to drive flawlessly the moving coil. Then, the physical behaviour of a generic electrodynamic loudspeaker is exclusively imposed by Eq.1 and naturally devoid of the numerous non linear distortions stemming from the unfortunate compound of both Eq.1 and $\mathbf{2}$ addressing the voltage drive policy $[7,8,9]$. Although the only advantage under voltage drive is a natural damping in the resonance region of the spectrum (owing to the motional impedance), effective filtering solutions can be nowadays considered to promote current-drive [3,6], as is shown in the appendix illustrating a mere generic scheme. Then, one could acknowledge that the widespread voltage drive policy stems from commonly established practice and classical electronic convenience only.

\section{HIGHLIGHTING THE RATIONALE OF THE APPROACH}

Predominance and self-governing property of Eq.1 are clearly highlighted with the straightforward electrical schemes depicted in Fig. 1: indeed Eq. 2 entails most untoward compounded electromotive forces (inductive and motional emf ), whereas any ideal current-drive policy makes the behaviour of the transducer independent of such extraneous e.m.f. Therefore, the sources of non linearity associated with the latter are naturally rejected with a functional current-drive. However, to be operational, an adequate filtering policy has to clear out the resonance regime together with prospective untoward high frequencies.

Loudspeaker equivalent to an active load in series with the voltage supply

$$
e_{(t)}=R_{e} \cdot i_{(t)}+L_{e} \cdot \frac{d i}{d t}+B_{l} \cdot \frac{d x}{d t}
$$

$E_{t}$ Electromotive Forces



$$
I=\frac{E_{g}-E_{t}}{R_{e}}
$$

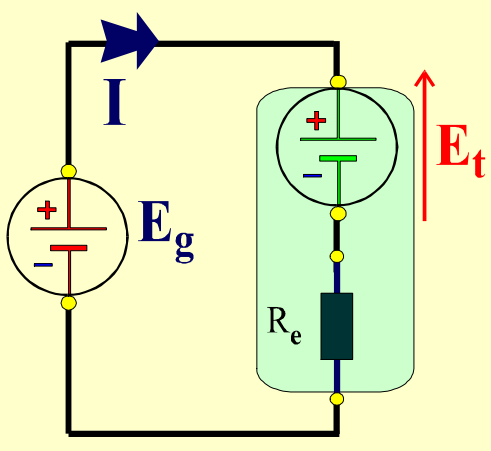

Voltage Control Thevenin Scheme

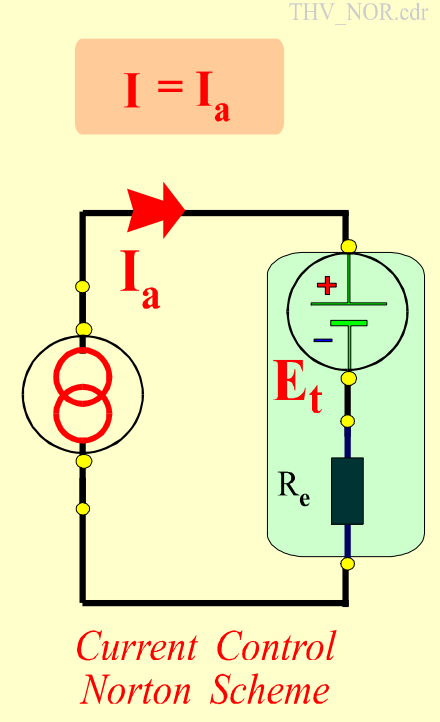

Fig. 1: Natural rejection of nonlinear components due to Eq.2 with an ideal current-drive policy 
Considering the displacement of the diaphragm and its derived quantities (speed and acceleration), the natural behaviour of the transducer only depends on Eq.1, where the nonlinear harmonic components stem from relevant effects regarding both parameters in the left member $\left(\mathbf{B}_{1}, \boldsymbol{L}_{\mathrm{e}}\right)$, and those included in the right one $\left(\boldsymbol{k}_{\mathrm{m}}, \boldsymbol{f}_{\mathrm{m}}\right)$. Since representative of the effective sound pressure the acceleration is the pivotal quantity.

For the purpose of comparison between numerical and analytical results, we refer to the special case of a commercialized midrange loudspeaker $\left(\right.$ Morel $^{\circledR}$ EM 428) as a reference model, considering its nominal parameters [10] together with its measured nonlinear characteristics obtained by way of a standard calibrating Klippel $^{\circledR}$ apparatus [11].

Nonlinear parameters can be described by way of Taylor classical truncated power-series $[12,13]$ that may be conveniently limited to the fifth order. Here, the following compact formulation allows us to describe harmonic distortions up to the fifth spectral line. To this end, the displacement can be described according to the following series:

$$
X_{(j \omega)}=\sum_{i=1}^{n} X_{i} \cdot e^{i \cdot(j \omega t)}=\sum_{i=1}^{n} X_{i} \cdot e^{i . \psi} \approx X_{1} \cdot e^{\psi}+X_{2} \cdot e^{2 . \psi}+X_{3} \cdot e^{3 . \psi}+X_{4} \cdot e^{4 . \psi}+X_{5} \cdot e^{5 . \psi}
$$

On the other hand, considering the dependence of a given nonlinear parameter noted $\lambda$ against a static value referred to as $\boldsymbol{x}$ (displacement in steady state), $\boldsymbol{\lambda}$ can be approached with a power-series expansion such as:

$$
\lambda(x)=\lambda_{0}+\lambda_{1} \cdot x+\lambda_{2} \cdot x^{2}+\lambda_{3} \cdot x^{3}+\lambda_{4} \cdot x^{4}+\lambda_{5} \cdot x^{5}
$$

For a given regime fitted with a fundamental frequency, the first fifth powers of the displacement $\mathbf{1}<\mathbf{k}<\mathbf{5}$ can be expressed with:

$$
X_{(j \omega)}^{\mathbf{k}}=X^{\mathbf{k}}=x_{1}^{k} \cdot e^{1 \cdot \psi}+x_{2}^{k} \cdot e^{2 \cdot \psi}+x_{3}^{k} \cdot e^{3 \cdot \psi}+x_{4}^{k} \cdot e^{4 \cdot \psi}+x_{5}^{k} \cdot e^{5 \cdot \psi}+\varepsilon
$$

\begin{tabular}{|c|c|c|c|c|c|c|}
\hline Displacement $\mathrm{X}$ & $\mathbf{X}^{\mathbf{k}}=$ & $x_{1}{ }^{k} \cdot \mathrm{e}^{1 \cdot \psi}+$ & $x_{2}{ }^{k} \cdot \mathrm{e}^{2 \cdot \psi}+$ & $x_{3}{ }^{k} \cdot e^{3 \cdot \psi}+$ & $x_{4}{ }^{k} \cdot e^{4 \cdot \psi}+$ & $x_{5}{ }^{k} \cdot \mathrm{e}^{5 \cdot \psi}$ \\
\hline Order I & $X^{1}$ & $x_{1}^{1}=X_{1}$ & $x_{2}^{1}=X_{2}$ & $x_{3}^{1}=\mathbf{X}_{3}$ & $x_{4}^{1}=X_{4}$ & $x_{5}^{1}=X_{5}$ \\
\hline Ordrer II & $\mathbf{X}^{2}$ & $x_{1}^{2}=0$ & $x_{2}^{2}=X_{1}^{2}$ & $x_{3}^{2}=2 X_{1} X_{2}$ & $x_{4}^{2}=X_{2}^{2}+2 X_{1} X_{3}$ & $x_{5}^{2}=X_{1} X_{4}+2 X_{2} X_{3}$ \\
\hline Order III & $\mathbf{X}^{3}$ & $x_{1}^{3}=0$ & $x_{2}{ }^{3}=0$ & $x_{3}{ }^{3}=\mathrm{X}_{1}{ }^{3}$ & $x_{4}^{3}=3 \mathrm{X}_{1}^{2} \mathrm{X}_{2}$ & $x_{5}{ }^{3}=2 X_{1}^{2} X_{3}+3 X_{1} X_{2}^{2}$ \\
\hline Order IV & $\mathbf{X}^{4}$ & $x_{1}^{4}=0$ & $x_{2}{ }^{4}=0$ & $x_{3}{ }^{4}=0$ & $x_{4}^{4}=\mathrm{X}_{1}{ }^{4}$ & $x_{5}{ }^{4}=4 X_{1}^{3} X_{2}$ \\
\hline Order V & $\mathrm{X}^{5}$ & $x_{1}^{5}=0$ & $x_{2}^{5}=0$ & $x_{3}{ }^{5}=0$ & $x_{4}{ }^{5}=0$ & $x_{5}^{5}=\mathrm{X}_{1}{ }^{5}$ \\
\hline
\end{tabular}

As each coefficient noted $\boldsymbol{x}_{\mathrm{i}}^{\mathrm{k}}$ related with Eq.5 can be easily determined by way of a classical truncated product, the set of relevant values is summed up in Table $\mathbf{I}$.

Table I: Coefficients values relative to the first fifth powers of the displacement $X$

\section{HARMONIC COMPONENTS OF DISPLACEMENT DUE TO THE FORCE FACTOR}

Aside from $\mathbf{B}_{\mathbf{1}}$ expanded according to Eq.4, we consider Eq.1 with linear parameters. The successive derivatives of the displacement (the speed $\dot{X}$, and the acceleration $\ddot{X}$ picturing the sound pressure) are developed so as to conform with respective left and right members (LM and RM) of Eq.1 rewritten as:

$$
\left[B_{l} \cdot I_{(j \omega)}\right]_{L_{-} \text {non-linear }}=\left[M_{m} \cdot \ddot{X}_{(j \omega)}+f_{m} \cdot \dot{X}_{(j \omega)}+k_{m} \cdot X_{(j \omega)}\right]_{R M_{- \text {Linear }}}
$$

Here, RM exclusively fitted with linear quantities, is classically processed as:

$$
\begin{aligned}
& X=X_{1} \cdot e^{1 \cdot \psi}+X_{2} \cdot e^{2 \cdot \psi}+X_{3} \cdot e^{3 \cdot \psi}+X_{4} \cdot e^{4 \cdot \psi}+X_{5} \cdot e^{5 \cdot \psi}+\varepsilon \\
& \dot{X}=j \omega X_{1} \cdot e^{1 \cdot \psi}+2 j \omega X_{2} \cdot e^{2 \cdot \psi}+3 j \omega X_{3} \cdot e^{3 \cdot \psi}+4 j \omega X_{4} \cdot e^{4 \cdot \psi}+5 j \omega X_{5} \cdot e^{5 \cdot \psi}+\varepsilon^{\prime}
\end{aligned}
$$


Gathering the relevant terms yields:

$$
\mathbf{R M}=M_{m} \cdot\left[X_{1} \cdot e^{1 \cdot \psi} \cdot \mathbf{P}_{1}+X_{2} \cdot e^{2 \cdot \psi} \cdot \mathbf{P}_{2}+X_{3} \cdot e^{3 \cdot \psi} \cdot \mathbf{P}_{3}+X_{4} \cdot e^{4 \cdot \psi} \cdot \mathbf{P}_{4}+X_{5} \cdot e^{5 \cdot \psi} \cdot \mathbf{P}_{5}\right]+\mathcal{E},
$$

where specific polynomial quantities may be defined with:

$$
\mathbf{P}_{\mathrm{n}}=\mathrm{n}^{2} \cdot\left[p^{2}+\frac{f_{m}}{M_{m}} \cdot \frac{1}{\mathrm{n}} \cdot p+\frac{k_{m}}{M_{m}} \cdot \frac{1}{\mathrm{n}^{2}}\right]=\mathrm{n}^{2} \cdot\left[p^{2}+\frac{2}{\tau} \cdot \frac{1}{\mathrm{n}} \cdot p+\omega_{0}^{2} \cdot \frac{1}{\mathrm{n}^{2}}\right] \cdot \quad\left[\mathbf{s}^{-2}\right]
$$

Then, considering a current excitation signal such as; $\boldsymbol{i}=\boldsymbol{i}_{\mathbf{0}} \cdot \mathrm{e}^{\mathrm{j} \omega \mathrm{t}}=\boldsymbol{i}_{\mathbf{0}} \cdot \mathrm{e}^{\boldsymbol{\psi}}$, Eq.6 may be written as:

$$
\left[b_{0}+b_{1}^{\prime} \cdot X+b_{2}^{\prime} \cdot X^{2}+b_{3}^{\prime} \cdot X^{3}+b_{4}^{\prime} \cdot X^{4}+b_{5}^{\prime} \cdot X^{5}+\varepsilon\right] \cdot i_{0} \cdot e^{\psi}=M_{m} \cdot \sum_{i=1}^{n} X_{i} \cdot e^{i \cdot \psi} \cdot \mathbf{P}_{\mathrm{i}}
$$

In this notation coefficients noted $\boldsymbol{b}$ ' relative to $X_{(\mathrm{j} \omega)}$ are given for each power with $\mathbf{b}^{{ }^{\prime}}{ }_{i}=\mathbf{b}_{\mathbf{i}} / \mathbf{2}^{\mathbf{i}}$, considering so coefficients $\mathbf{b}_{\mathbf{i}}(0 \leq \mathbf{i} \leq 5)$ measured in steady state [6]. Then, assuming as relevant the identification of each component to a given harmonic frequency, the quantities summed up in Table I allow us to point out :

$$
\begin{aligned}
& \boldsymbol{M}_{\mathrm{m}} \cdot \mathbf{X}_{\mathbf{1}} \cdot \mathbf{P}_{\mathbf{1}}=\mathbf{b}_{\mathbf{0}} \cdot \mathbf{i}_{0} \\
& M_{\mathrm{m}} \cdot \mathrm{X}_{2} \cdot \mathrm{P}_{2}=0+\mathrm{b}_{1}, \mathrm{i}_{0} \cdot \mathrm{X}_{1} \\
& M_{\mathrm{m}} \cdot \mathrm{X}_{3} \cdot \mathrm{P}_{3}=0+\mathrm{b}^{\prime}{ }_{1} \cdot \mathrm{i}_{0} \cdot \mathrm{X}_{2}+\mathrm{b}_{2}{ }_{2} \cdot \mathrm{i}_{0} \cdot \mathrm{X}_{1}{ }^{2} \\
& M_{\mathrm{m}} \cdot \mathrm{X}_{4} \cdot \mathrm{P}_{4}=0+\mathrm{b}^{\prime} \cdot \mathrm{i}_{0} \mathrm{X}_{3}+\mathrm{b}^{\prime} \cdot{ }_{2} \cdot \mathrm{i}_{0} \cdot 2 \cdot \mathrm{X}_{1} \cdot \mathrm{X}_{2}+\mathrm{b}{ }_{3} \cdot \mathrm{i}_{0} \cdot \mathrm{X}_{1}{ }^{3} \\
& M_{\mathrm{m}} \cdot \mathrm{X}_{5} \cdot \mathrm{P}_{5}=0+\mathrm{b}^{\prime}{ }_{1} \cdot \mathrm{i}_{0} \cdot \mathrm{X}_{4}+\mathrm{b}^{\prime}{ }_{2} \cdot \mathrm{i}_{0} \cdot\left(\mathrm{X}_{2}{ }^{2}+2 \cdot \mathrm{X}_{1} \cdot \mathrm{X}_{3}\right)+\mathrm{b}^{\prime} \cdot \mathrm{i}_{0} \cdot 3 \cdot \mathrm{X}_{1}{ }^{2} \cdot \mathrm{X}_{2}+\mathrm{b}_{4}{ }_{4} \cdot \mathrm{i}_{0} \cdot \mathrm{X}_{1}{ }^{4} \\
& M_{\mathrm{m}} \cdot \mathrm{X}_{6} \cdot \mathrm{P}_{6}=0+\mathrm{b}^{\prime}{ }_{1} \cdot \mathrm{i}_{0} \cdot \mathrm{X}_{5}+\mathrm{b}^{\prime}{ }_{2} \cdot \mathrm{i}_{0} \cdot\left(\mathrm{X}_{1} \cdot \mathrm{X}_{4}+2 \cdot \mathrm{X}_{2} \cdot \mathrm{X}_{3}\right)+\mathrm{b}^{\prime}{ }_{3} \cdot \mathrm{i}_{0} \cdot\left(2 \mathrm{X}_{1}{ }^{2} \cdot \mathrm{X}_{3}+3 \cdot \mathrm{X}_{1} \cdot \mathrm{X}_{2}{ }^{2}\right)+\mathrm{b}^{\prime}{ }_{4} \cdot \mathrm{i}_{0} \cdot 4 \mathrm{X}_{1}{ }^{3} \cdot \mathrm{X}_{2}+\mathrm{b}^{\prime}{ }_{5} \cdot \mathrm{i}_{0} \cdot \mathrm{X}_{1}{ }^{5}
\end{aligned}
$$

Such a writing is noticeably simplified when considering auxiliary coefficients $\mathbf{c}_{\mathbf{k}}=\mathbf{b}{ }_{\mathbf{k}} \cdot \mathbf{i}_{0} / \mathbf{M}_{\mathbf{m}}$ together with inverted polynomial quantities such as:

$$
\mathbf{F}_{\mathrm{n}}=\frac{1}{\mathbf{P}_{\mathrm{n}}}=\frac{1}{\mathrm{n}^{2} \cdot\left[p^{2}+\frac{f_{m}}{M_{m}} \cdot \frac{1}{\mathrm{n}} \cdot p+\frac{k_{m}}{M_{m}} \cdot \frac{1}{\mathrm{n}^{2}}\right]} \quad \text { with } \forall \mathrm{n}, \underset{\omega \rightarrow 0}{\operatorname{Lim}}\left(\mathbf{F}_{\mathrm{n}}\right)=\frac{1}{\omega_{0}^{2}} \quad\left[\mathbf{s}^{2}\right]
$$

Then the set of relations Eqs.11 allows each component to be successively determined from its former ones:

$\mathbf{X}_{1}=\mathbf{F}_{1} \cdot\left[\mathrm{c}_{0}\right]$

$\mathbf{X}_{2}=\mathbf{F}_{2} \cdot\left[\mathbf{c}_{1} \cdot \mathbf{X}_{1}\right]$

$X_{3}=F_{3} \cdot\left[c_{1} \cdot X_{2}+c_{2} \cdot X_{1}^{2}\right]$

$X_{4}=F_{4} \cdot\left[c_{1} \cdot X_{3}+c_{2} \cdot 2 \cdot X_{1} \cdot X_{2}+c_{3} \cdot X_{1}^{3}\right]$

$X_{5}=F_{5} \cdot\left[c_{1} \cdot X_{4}+c_{2} \cdot\left(X_{2}^{2}+2 \cdot X_{1} \cdot X_{3}\right)+c_{3} \cdot 3 \cdot X_{1}^{2} \cdot X_{2}+c_{4} \cdot X_{1}^{4}\right]$

$X_{6}=F_{6} \cdot\left[c_{1} \cdot X_{5}+c_{2} \cdot\left(X_{1} \cdot X_{4}+2 \cdot X_{2} \cdot X_{3}\right)+c_{3} \cdot\left(2 X_{1}{ }^{2} \cdot X_{3}+3 \cdot X_{1} \cdot X_{2}{ }^{2}\right)+c_{4} \cdot 4 X_{1}^{3} \cdot X_{2}+c_{5} \cdot X_{1}{ }^{5}\right]$

Such components may be also determined on their own, with for instance as regard the first fourth lines:

$\mathbf{X}_{1}=\left[\mathbf{c}_{0}\right] . \mathbf{F}_{1}$

$X_{2}=\left[c_{0} \cdot c_{1}\right] \cdot F_{1} \cdot F_{2}$

$\mathrm{X}_{3}=\left[\mathrm{c}_{0}{ }^{2} \cdot \mathbf{c}_{2}\right] \cdot \mathrm{F}_{1}{ }^{2} \cdot \mathrm{F}_{3}+\left[\mathrm{c}_{0} \cdot \mathrm{c}_{1}\right] \cdot \mathrm{F}_{1} \cdot \mathrm{F}_{2} \cdot \mathrm{F}_{3}$

$X_{4}=\left[c_{0}{ }^{3} \cdot c_{3}\right] \cdot F_{1}{ }^{3} \cdot F_{4}+2 \cdot\left[c_{0}{ }^{2} \cdot c_{1} \cdot c_{2}\right] \cdot F_{1}{ }^{2} \cdot F_{2} \cdot F_{4}+\left[c_{0}{ }^{2} \cdot c_{1} \cdot c_{2}\right] \cdot F_{1}{ }^{2} \cdot F_{3} \cdot F_{4}+\left[c_{0} \cdot c_{1}{ }^{3}\right] \cdot F_{1} \cdot F_{2} \cdot F_{3} \cdot F_{4}$

$\mathbf{X}_{\mathbf{5}}$ and $\mathbf{X}_{\mathbf{6}}$ are not described in Eqs.14 due to their useless intricate shape besides being accessible with Eqs.13 for the purpose of illustration.

\subsection{Application case and numerical specification to assess the results}

As the sound pressure hinges on the acceleration of the diaphragm $[1,3,6]$ any relevant use of the latter results must consider the following transformations (for a given component regarding the $\mathbf{n}^{\text {th }}$ order).

$$
A_{\mathrm{n}}=-\omega^{2} \cdot \mathrm{n}^{2} \cdot X_{\mathrm{n}} \quad\left[\mathrm{m} / \mathrm{s}^{2}\right]
$$

At first we consider the reference transducer whose measured $\mathbf{B}_{1}$ static coefficients and nominal parameters are respectively summed up in Table II and Table III. Then, a moderate current regime is considered with 
a $100 \mathrm{~mA}$ amplitude for the purpose of comparison of calculated acceleration values. Besides, results are also investigated with a numerical simulation operated with the Simulink ${ }^{\circledR}$ software [6].

\begin{tabular}{|cccccc|}
\hline $\mathbf{b}_{0}[\mathrm{~N} / \mathrm{A}]$ & $\mathbf{b}_{1}[\mathrm{~N} /(\mathbf{A} \cdot \mathrm{mm})]$ & $\mathbf{b}_{2}\left[\mathrm{~N} /\left(\mathbf{A} \cdot \mathrm{mm}^{2}\right)\right]$ & $\mathbf{b}_{3}\left[\mathrm{~N} /\left(\mathbf{A} \cdot \mathrm{mm}^{3}\right)\right]$ & $\mathbf{b}_{4}\left[\mathrm{~N} /\left(\mathbf{A} \cdot \mathrm{mm}^{4}\right)\right]$ & $\left.\mathbf{b}_{5}\left[\mathrm{~N} /(\mathbf{A} \cdot \mathrm{mm})^{5}\right)\right]$ \\
$\mathbf{5 , 9 3 0 5}$ & $\mathbf{0 , 0 6 9 3 0 0}$ & $\mathbf{- 0 , 2 3 5 1 2}$ & $\mathbf{- 0 , 0 8 1 4 4 9}$ & $\mathbf{0 , 0 1 1 2 6 9}$ & $\mathbf{0 , 0 0 4 2 4 7 8}$ \\
\hline
\end{tabular}

Table II: Force factor coefficients entailing the investigated nonlinear behaviour of the transducer

\begin{tabular}{|c|c|c|}
\hline Morel ${ }^{\circledR}$ Midrange & EM 428-8 $\Omega$ & $\varnothing 4 ", \varnothing 2.1 "$ voicecoil \\
\hline Nominal parameters & Theoretical values & Measured values \\
\hline Mass $\boldsymbol{M}_{\mathrm{m}}$ & $6,55 \mathrm{~g}$ & $6,529 \mathrm{~g}$ \\
\hline Mechanical damping $f_{\mathrm{m}}$ & $0,86 \mathrm{~kg} / \mathrm{s}$ & $1,239 \mathrm{~kg} / \mathrm{s}$ \\
\hline Rigidity $k_{\mathrm{m}}$ & $1136 \mathrm{~N} / \mathrm{m}$ & $1938 \mathrm{~N} / \mathrm{m}$ \\
\hline Resonance Freq. $F_{0}$ & $66,29 \mathrm{~Hz}$ & $86,7 \mathrm{~Hz}$ \\
\hline Force factor $B_{1}$ & 5,4 T.m & 5,934 T.m \\
\hline Resistance DC $\mathbf{R}_{\mathrm{e}}$ & $5,4 \Omega$ & $5,41 \Omega$ \\
\hline Inductance (para) $\mathbf{L}_{\mathbf{e}}$ & $0,36 \mathrm{mH}$ & $0,356 \mathrm{mH}$ \\
\hline Mechanic Quality factor $Q_{\mathrm{m}}$ & 3,03 & 2,871 \\
\hline
\end{tabular}

Table III: Theoretical and measured nominal parameters of the EM 428 reference transducer

According to Table II, the pattern associated to the force factor against displacement is depicted in Fig.2, where both even and odd parts are also illustrated. The operational range is voluntarily exceedingly spanned so as to highlight the relevant parts to be considered.



Fig. 2: Static changes measured for the force factor against displacement (Klippel ${ }^{\circledR}$ testing bench)

On the other hand, Simulink ${ }^{\circledR}$ is a block diagram environment for multidomain simulation and Model-Based Design. It supports system-level design, simulation, automatic code. and continuous test. Then, as the representative equations of a transducer depend both on time and displacement, such a numerical solver can take into account all the involved parameters. All physical quantities, such as displacement, speed and acceleration, can be advantageously modelized considering any parameter described according to Eq.4. Then, nonlinear quantities can be coupled with articulate function blocks allowing to account for the evolutive parameters $\left[\mathbf{B}_{\mathbf{l}}(\mathrm{x}), \boldsymbol{k}_{\mathrm{m}}(\mathrm{x}), \mathbf{L}_{\mathbf{e}}(\mathrm{x}), \boldsymbol{f}_{\mathrm{m}}(\mathrm{v})\right]$. As depicted in $\mathbf{F i g . 3}$, the model relies on processing the 
running displacement $\mathrm{x}(\mathrm{t})$ as a feedback data for computing sequentially each other parameter. Indeed, the numerical scheme illustrated in Fig.3 is fitted for the current supply mode [6]. As enabled with this Simulink ${ }^{\circledR}$ model, the current excitation signal can be processed, yielding both displacement, speed, and acceleration values in sampled time. Such behaviours are simulated before processing with a classical Fast Fourier Transform. As in the literature, the $0 \mathrm{~dB}$ reference line level is that of the fundamental. Then, fundamental spectral lines can be investigated together with their respective sets of harmonics due to nonlinear distortions. Here, aside from $\mathbf{B}_{1}$ all the other lumped parameters are considered at their rest position.

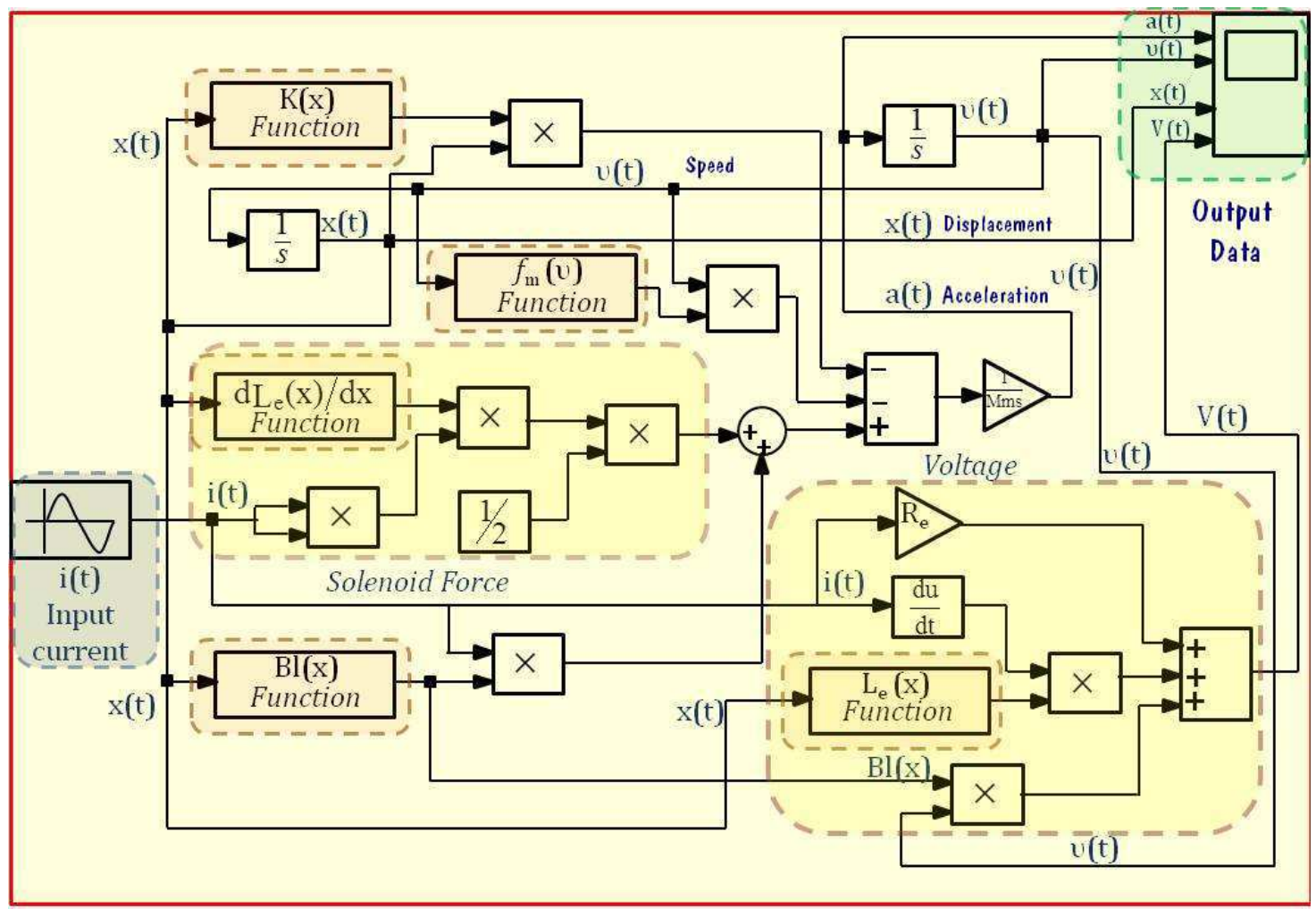

Fig. 3: Simulink ${ }^{\circledR}$ nonlinear numerical evolutive model for a current driven loudspeaker

\subsection{Comparison and assessment of the acceleration values}

Considering the abovementioned conditions, respective results regarding both analytic and numerical approaches are depicted in Fig.4. Aside from the first low frequency values associated with the sixth line, results are in good agreement. As an illustration of the acceleration reference level associated with the fundamental, several sampled values are summed up in Table IV. 


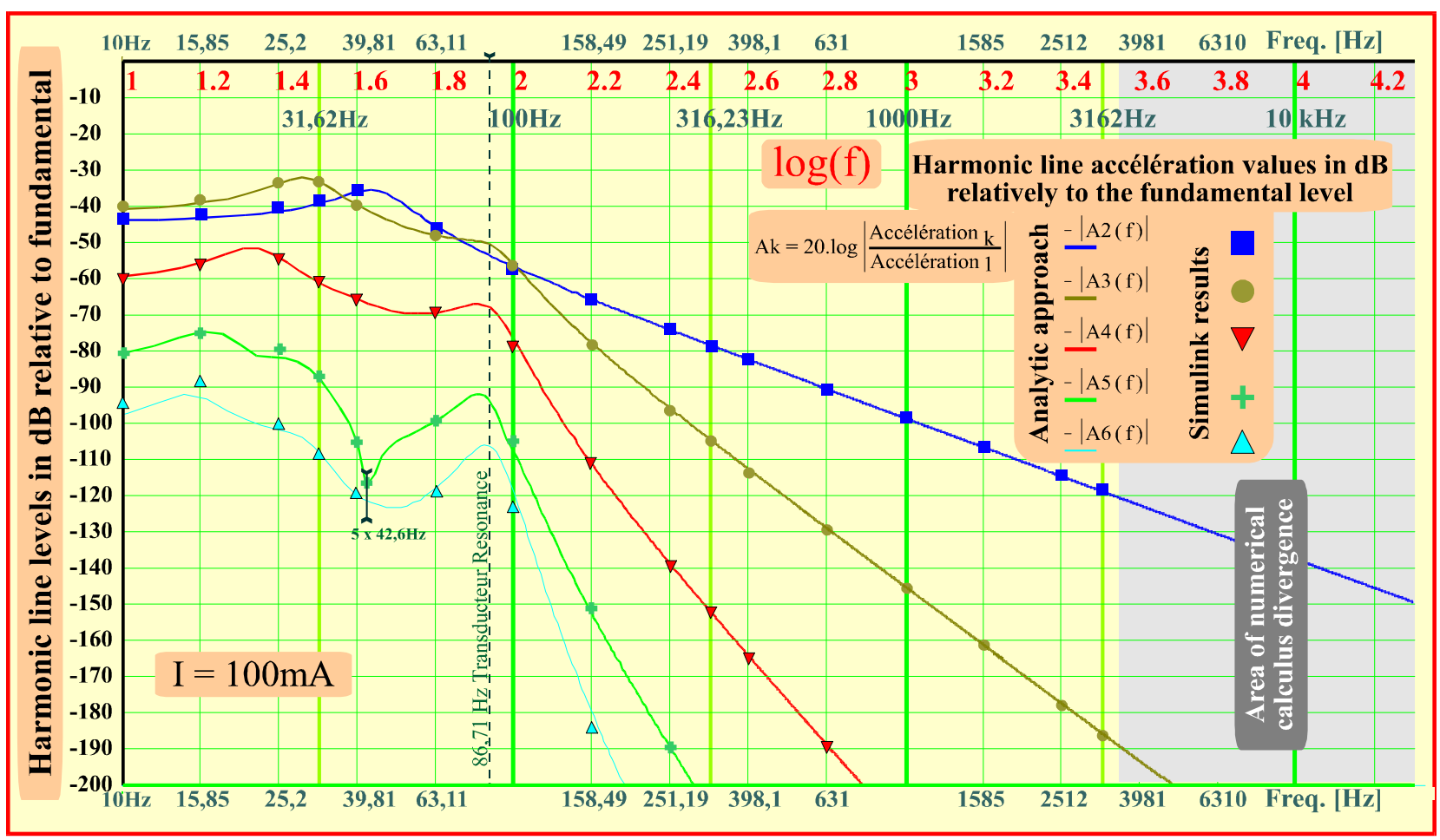

Fig. 4: Behaviour of the first six harmonic lines according to both analytic and Simulink ${ }^{\circledR}$ approaches

\begin{tabular}{|c|c|c|c|c|c|}
\hline $\begin{array}{c}A_{1}\left(\mathbf{m} / \mathbf{s}^{2}\right) \\
F=10 \mathrm{~Hz}\end{array}$ & $\begin{array}{c}A_{1}\left(\mathbf{m} / \mathbf{s}^{2}\right) \\
F=31,62 \mathrm{~Hz}\end{array}$ & $\begin{array}{c}A_{1}\left(\mathbf{m} / \mathbf{s}^{2}\right) \\
F=100 \mathrm{~Hz}\end{array}$ & $\begin{array}{c}A_{1}\left(\mathbf{m} / \mathbf{s}^{2}\right) \\
F=316,23 \mathrm{~Hz}\end{array}$ & $\begin{array}{c}A_{1}\left(\mathbf{m} / \mathbf{s}^{2}\right) \\
F=1000 \mathrm{~Hz}\end{array}$ & $\begin{array}{c}A_{1}\left(\mathbf{m} / \mathbf{s}^{2}\right) \\
F=3162 \mathrm{~Hz}\end{array}$ \\
\hline 1,22 & 13,74 & 230,97 & 97.69 & 91,48 & 90,91 \\
\hline
\end{tabular}

Table IV: Acceleration reference values associated to the fundamental (current $100 \mathrm{~mA}$ )

The physical meaning regarding the lines pattern shown in Fig.4 will be discussed hereafter since classical representations referred to the fundamental have clearly to be argued.

\section{INVESTIGATING ON THE HARMONIC DISTORTION DUE TO THE SOLENOID FORCE}

Considering the extraneous driving force within the left member of Eq.1, the mechanism can be assessed on its own so as to compare its untoward effects with the other sources of distortion. An exclusive solenoid drive would yield:

$$
\frac{1}{2} \cdot i^{2} \cdot \frac{d L_{e}}{d x}=M_{m} \cdot \frac{d^{2} x}{d t^{2}}+f_{m} \cdot \frac{d x}{d t}+k_{m} \cdot x
$$

A very simple way to deal with such an interaction is to regard the quadratic character of the driving current in Eq. 16, with $i(t)=i_{0} \cdot \cos (\omega t)$ and $\cos ^{2}(\omega t)=1 / 2 \cdot[1+\cos (2 \omega t)]$. The static component acts in continuously taking back the voice coil, and is superimposed with the fluctuation at the double-frequency. On the other hand, Table $\mathbf{V}$ illustrates the measurements values relative to the inductance power series coefficients.

\begin{tabular}{|cccccc||}
\hline \hline$l_{0} \mathrm{mH}$ & $l_{1}[\mathrm{mH} / \mathrm{mm}]$ & $l_{2}\left[\mathrm{mH} / \mathrm{mm}^{2}\right]$ & $l_{3}\left[\mathrm{mH} / \mathrm{mm}^{3}\right]$ & $l_{4}\left[\mathrm{mH} / \mathrm{mm}^{4}\right]$ & $1_{5}\left[\mathrm{mH} / \mathrm{mm}^{5}\right]$ \\
0,35099 & $-0,016090$ & $-0,0079749$ & 0,00058492 & 0,00018508 & $7,1582.10^{-6}$ \\
\hline \hline
\end{tabular}

Table V : Inductance nonlinear coefficient values

Then, assuming a significant current value with $\mathbf{i}_{0}=1 \mathrm{~A}$, at the first order, the entailed static displacement noted $X_{\text {st }}$ would be close to: 


$$
X_{\mathrm{st}}=\frac{1}{4} \cdot \frac{i_{0}^{2}}{k_{m}} \cdot \frac{d L_{e}}{d x} \approx \frac{1}{4} \cdot \frac{i_{0}^{2 \cdot}}{k_{m}} \cdot 1_{1}
$$

According to Table III, the double-frequency fluctuation is superposed with a static displacement value given with: $\boldsymbol{X}_{\mathbf{s t}}=\mathbf{- \mathbf { 5 , 2 }} \cdot \mathbf{1 0 ^ { - 7 }} \mathbf{m}$. Now, for the purpose of comparison the forces involved with both Lorentz useful mechanism and the solenoid extraneous one can also be evaluated. A quasi-static regime with a unity current yields a Lorentz force $\mathbf{F}_{\mathbf{L}}=\mathbf{B}_{1} \mathbf{.} \mathbf{i} \approx \mathbf{+ 5 , 9 3} \mathbf{N}$ moving forward the diaphragm. On the other hand, with $[\mathrm{dL} / \mathrm{dx}=-0,016 \mathrm{H} / \mathrm{m}]$, the solenoid force noted $\mathbf{F}_{\mathbf{S}}$ features a peak to peak absolute value given with:

$$
\mathbf{F}_{\mathbf{S}}=\left|\frac{1}{2} \cdot i^{2} \cdot \frac{d L_{e}}{d x}\right| \approx \frac{1}{2} \cdot 1^{2} \cdot\left|\mathrm{I}_{1}\right|=0,008 \mathrm{~N}
$$

Such a tiny value, about a $\mathbf{0 , 3 5 \%}$ magnitude of the Lorentz force allows us to posit a quasi linear behaviour as regards the double-frequency component superimposed with the static backward displacement. Then considering the double angular frequency $\boldsymbol{\Phi}=\mathbf{2} . \boldsymbol{\omega}$, the solenoid distortion component can be written:

$$
X_{\sigma}=\frac{1}{4} \cdot 1_{1} \cdot \frac{1}{M_{m}} \cdot \frac{1}{\mathbf{P}_{1(\varpi)}} \text { with } \mathbf{P}_{1(\varpi)}=\left[-\varpi^{2}+\frac{f_{m}}{M_{m}} \cdot j \cdot \varpi+\frac{k_{m}}{M_{m}}\right] \quad \text { [m] }
$$

As a result, the relevant acceleration (quantity to be considered for the audio signal), is given with:

$$
\left[A_{\varpi}\right]_{\sigma=2 \cdot \omega}=\frac{1}{4} \cdot 1_{1} \cdot \frac{1}{M_{m}} \cdot \frac{-\varpi^{2}}{\mathbf{P}_{1(\varpi)}}
$$

$\left[\mathrm{m} / \mathrm{s}^{2}\right]$

Results of both Eq. 19 and 20 are compared with the Simulink ${ }^{\circledR}$ numerical simulation as depicted in Fig. 5 for two different values of the driving current.

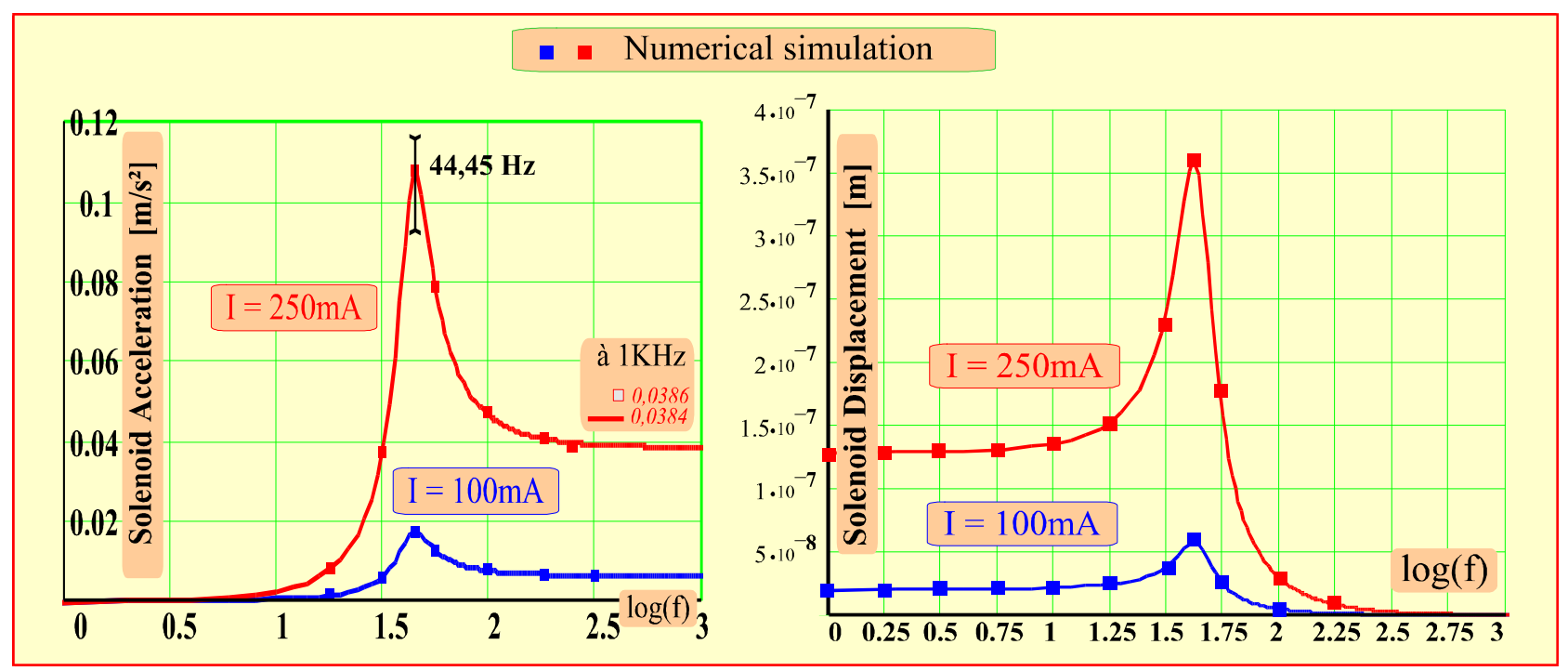

Fig. 5: Assessment of the solenoid effect

As the manifestation of the effect occurs at twice the shown frequency, it is clear from Fig.5 that the extrema appearing at $\mathbf{4 4 , 4 5} \mathbf{H z}$ corresponds quite closely $(\mathbf{8 8 , 9 0 ~} \mathbf{H z})$ but not exactly with the mechanical resonance frequency of the transducer $(\mathbf{8 6 , 7} \mathbf{~ H z})$. As a most important point that markedly differs from the other distortion sources, the solenoid effect doesn't abate as the frequency is increased.

\section{INVESTIGATING ON THE RIGIDITY}

The stiffness or rigidity parameter $\boldsymbol{k}_{\mathrm{m}}$ may be investigated either while considering its own power-series or that of its opposite quantity the so-called compliance $\mathbf{C}_{\mathrm{m}}=\mathbf{1} / \boldsymbol{k}_{\mathrm{m}}$. Measured coefficient values for the stiffness are summed up in Table VI.

\begin{tabular}{||cccccc||}
\hline$k_{0}[\mathrm{~N} / \mathrm{mm}]$ & $k_{1}\left[\mathrm{~N} / \mathrm{mm}^{2}\right]$ & $k_{2}\left[\mathrm{~N} / \mathrm{mm}^{3}\right]$ & $k_{3}\left[\mathrm{~N} / \mathrm{mm}^{4}\right]$ & $k_{4}\left[\mathrm{~N} / \mathrm{mm}^{5}\right]$ & $k_{5}\left[\mathrm{~N} / \mathrm{mm}^{6}\right]$ \\
1,579 & 0,33332 & 0.058674 & 0.036590 & 0.025980 & 0 \\
\hline
\end{tabular}




\section{Table VI: Nonlinear coefficient values for the suspension stiffness}

Symmetry properties can be analysed the same way than that of the force factor, leading then to specific harmonic components as will be discussed hereafter when dealing again with the force factor analysis.

\subsection{Harmonic components of displacement due to rigidity}

Considering again Eq.6, the right member (RM) is now nonlinear, and Eq.7a has to be processed according to the power series describing the stiffness fitted with values noted $\boldsymbol{k}$ ' and defined as:

$$
K_{(X)}=\sum_{i=0}^{n} k_{i}^{\prime} \cdot X^{i}=\frac{1}{2^{0}} \cdot k_{0}+\frac{1}{2^{1}} \cdot k_{1} \cdot X+\frac{1}{2^{2}} \cdot k_{2} \cdot X^{2}+\frac{1}{2^{3}} \cdot k_{3} \cdot X^{3}+\frac{1}{2^{4}} \cdot k_{4} \cdot X^{4}+\mathcal{E}
$$

Then Eq.6 can be reformulated as:

$$
\begin{aligned}
B_{1} \cdot \mathrm{i}_{0} \cdot e^{1 \cdot \psi}=- & M_{m} \cdot \omega^{2} \cdot\left[X_{1} \cdot e^{1 \cdot \psi}+4 X_{2} \cdot e^{2 \cdot \psi}+9 X_{3} \cdot e^{3 \cdot \psi}+16 X_{4} \cdot e^{4 \cdot \psi}+25 X_{5} \cdot e^{5 \cdot \psi}+\varepsilon\right] \\
& +j \cdot \omega \cdot f_{m} \cdot\left[X_{1} \cdot e^{1 \cdot \psi}+2 X_{2} \cdot e^{2 \cdot \psi}+3 X_{3} \cdot e^{3 \cdot \psi}+4 X_{4} \cdot e^{4 \cdot \psi}+5 X_{5} \cdot e^{5 \cdot \psi}+\varepsilon\right] \\
& +k_{0}^{\prime} \cdot\left[X_{1} \cdot e^{1 \cdot \psi}+X_{2} \cdot e^{2 \cdot \psi}+X_{3} \cdot e^{3 \cdot \psi}+X_{4} \cdot e^{4 \cdot \psi}+X_{5} \cdot e^{5 \cdot \psi}+\varepsilon\right] \\
& +k_{1}^{\prime} \cdot\left[X_{1}^{2} \cdot e^{2 \cdot \psi}+2 X_{1} X_{2} \cdot e^{3 \cdot \psi}+\left(X_{2}^{2}+2 X_{1} \cdot X_{3}\right) \cdot e^{4 \cdot \psi}+\left(X_{1} \cdot X_{4}+2 X_{2} \cdot X_{3}\right) \cdot e^{5 \cdot \psi}+\varepsilon\right] \\
& +k_{2}^{\prime} \cdot\left[X_{1}^{3} \cdot e^{3 \cdot \psi}+3 X_{1}^{2} X_{2} \cdot e^{4 \cdot \psi}+\left(2 X_{1}^{2} \cdot X_{3}+3 X_{1} \cdot X_{2}^{2}\right) \cdot e^{5 \cdot \psi}+\varepsilon\right] \\
& +k_{3}^{\prime} \cdot\left[X_{1}^{4} \cdot e^{4 \cdot \psi}+4 X_{1}^{3} X_{2} \cdot e^{5 \cdot \psi}+\varepsilon\right] \\
& +k_{4}^{\prime} \cdot\left[X_{1}^{5} \cdot e^{5 \cdot \psi}+\varepsilon\right]
\end{aligned}
$$

Then, with regards to Table I, displacement values can be determined and each component identified according to the aforementioned way:

$$
\begin{aligned}
& \boldsymbol{M}_{\mathrm{m}} \cdot \mathbf{X}_{\mathbf{1}} \cdot \mathbf{P}_{\mathbf{1}}=\boldsymbol{B}_{1} \cdot \mathbf{i}_{\mathbf{0}} \quad \text { [fundamental frequency] } \\
& M_{\mathrm{m}} \cdot \mathrm{X}_{2} \cdot \mathbf{P}_{2}=-\left[k^{\prime}{ }_{1} \cdot \mathrm{X}_{1}^{2}\right] \\
& M_{\mathrm{m}} \cdot \mathrm{X}_{3} \cdot \mathrm{P}_{3}=-\left[2 \cdot k_{1}^{\prime} \cdot \mathrm{X}_{1} \cdot \mathrm{X}_{2}+k^{\prime}{ }_{2} \cdot \mathrm{X}_{1}{ }^{3}\right] \\
& M_{\mathrm{m}} \cdot \mathrm{X}_{4} \cdot \mathrm{P}_{4}=-\left[k^{\prime}{ }_{1} \cdot\left(\mathrm{X}_{2}{ }^{2}+2 \cdot \mathrm{X}_{1} \cdot \mathrm{X}_{3}\right)+k_{2}^{\prime} \cdot\left(3 \cdot \mathrm{X}_{1}^{2} \cdot \mathrm{X}_{2}\right)+k^{\prime}{ }_{3} \cdot \mathrm{X}_{1}{ }^{4}\right] \\
& M_{\mathrm{m}} \cdot \mathrm{X}_{5} \cdot \mathrm{P}_{5}=-\left[k^{\prime} \cdot\left(\mathrm{X}_{1} \cdot \mathrm{X}_{4}+2 \mathrm{X}_{2} \cdot \mathrm{X}_{3}\right)+k_{2}^{\prime} \cdot\left(2 \cdot \mathrm{X}_{1}^{2} \cdot \mathrm{X}_{3}+3 \cdot \mathrm{X}_{1} \cdot \mathrm{X}_{2}{ }^{2}\right)+k^{\prime} \cdot\left(4 \cdot \mathrm{X}_{1}^{3} \cdot \mathrm{X}_{2}\right)+k_{4}{ }_{4} \cdot \mathrm{X}_{1}{ }^{5}\right]
\end{aligned}
$$

As before, for the purpose of simplification, auxiliary coefficients can be defined such as:

$$
\boldsymbol{\varphi}=\boldsymbol{B}_{1} \cdot \mathbf{i}_{0} / \boldsymbol{M}_{\boldsymbol{m}} \quad \text { Relative mass strength } \quad[\mathrm{N} / \mathrm{kg}]
$$

and: $\quad \mathrm{g}_{i}=\frac{k_{i}}{2^{i}} \cdot \frac{-1}{M_{m}}$

$$
\left[\mathrm{N} /\left(\mathrm{m}^{\mathrm{i}+1} \cdot \mathrm{kg}\right)\right]
$$

Then each component may be written as follows according to its former ones:

$$
\begin{array}{lll}
X_{1}=F_{1} \cdot[\varphi] & & \\
X_{2}=F_{2} \cdot\left[g_{1} \cdot X_{1}{ }^{2}\right] & & \\
X_{3}=F_{3} \cdot\left[g_{1} \cdot 2 \cdot X_{1} \cdot X_{2}\right. & \left.+g_{2} \cdot X_{1}{ }^{3}\right] & \\
X_{4}=F_{4} \cdot\left[g_{1} \cdot\left(X_{2}{ }^{2}+2 \cdot X_{1} \cdot X_{3}\right)\right. & +g_{2} \cdot 3 \cdot X_{1}{ }^{2} \cdot X_{2} & \left.+g_{3} \cdot X_{1}{ }^{4}\right] \\
X_{5}=F_{5} \cdot\left[g_{1} \cdot\left(X_{1} \cdot X_{4}+2 \cdot X_{2} \cdot X_{3}\right)\right. & +g_{2} \cdot\left(2 X_{1}{ }^{2} \cdot X_{3}+3 \cdot X_{1} \cdot X_{2}{ }^{2}\right) & \left.+g_{3} \cdot 4 X_{1}{ }^{3} \cdot X_{2}+c_{5} \cdot X_{1}{ }^{5}\right]
\end{array}
$$

Those components may also be defined on their own, considering for instance the first four ones (the fifth one is not described as such, owing to a useless cumbersomeness):

$$
\begin{aligned}
& X_{1}=\varphi \cdot F_{1} \\
& X_{2}=\varphi^{2} \cdot g_{1} \cdot F_{1}{ }^{2} \cdot F_{2} \\
& X_{3}=\varphi^{3} \cdot\left[2 \cdot g_{1}{ }^{2} \cdot F_{2}+g_{2}\right] \\
& X_{4}=\varphi^{4} \cdot\left[g_{1} \cdot\left(F_{2}{ }^{2} \cdot g_{1}{ }^{2}+2 \cdot F_{3} \cdot\left(2 \cdot g_{1}{ }^{2} \cdot F_{2}+g_{2}\right)\right)+3 \cdot g_{1} \cdot g_{2} \cdot F_{2}+g_{3}\right]
\end{aligned}
$$




\subsection{Application cases and comparison with numerical results}

As before, acceleration values are determined with Eq.15, and relevant specifications regarding the considered driving current. In a first case, with all parameters aside $\boldsymbol{k}_{\mathrm{m}}$ being considered at rest ( $c f$. Table III), the driving current is fixed with a $100 \mathbf{~ m A}$ amplitude value. Then, with the classical way to refer all harmonic component levels to the fundamental values, Table VII makes clear the most significant level values regarding this special case.

\begin{tabular}{|c|c|c|c|c|c|}
\hline $\begin{array}{c}A_{1}\left(\mathrm{~m} / \mathrm{s}^{2}\right) \\
\mathbf{F}=10 \mathrm{~Hz}\end{array}$ & $\begin{array}{c}A_{1}\left(\mathrm{~m} / \mathrm{s}^{2}\right) \\
\mathbf{F}=\mathbf{3 1 , 6 2} \mathrm{Hz}\end{array}$ & $\begin{array}{c}A_{1}\left(\mathrm{~m} / \mathrm{s}^{2}\right) \\
F=100 \mathrm{~Hz}\end{array}$ & $\begin{array}{c}A_{1}\left(\mathrm{~m} / \mathrm{s}^{2}\right) \\
\mathrm{F}=\mathbf{3 1 6 , 2 3 ~ H z}\end{array}$ & $\begin{array}{c}A_{1}\left(\mathrm{~m} / \mathrm{s}^{2}\right) \\
F=1000 \mathrm{~Hz}\end{array}$ & $\begin{array}{c}A_{1}\left(\mathrm{~m} / \mathrm{s}^{2}\right) \\
F=3162 \mathrm{~Hz}\end{array}$ \\
\hline 1,505 & 17,391 & 181,87 & 96,22 & $\mathbf{9 1 , 3 5}$ & $\mathbf{9 0 , 8 8}$ \\
\hline
\end{tabular}

\section{Table VII: Level values of the fundamental line with a $100 \mathrm{~mA}$ current driving}

Moreover, the behaviour of the first fifth components is depicted on Fig.6. Here, the analytic model seems less fitting with the numerical approach whose values are ensured with another calculation developed with the Mathematica ${ }^{\circledR}$ software. Indeed, at a frequency close to $25 \mathrm{~Hz}$ the fifth component values (then at 125 $\mathrm{Hz}$ ) shows off a discrepancy between calculated levels reaching up to $7 \mathrm{~dB}$. Aside from this noticeable local divergence the analytic model seems to behave properly.

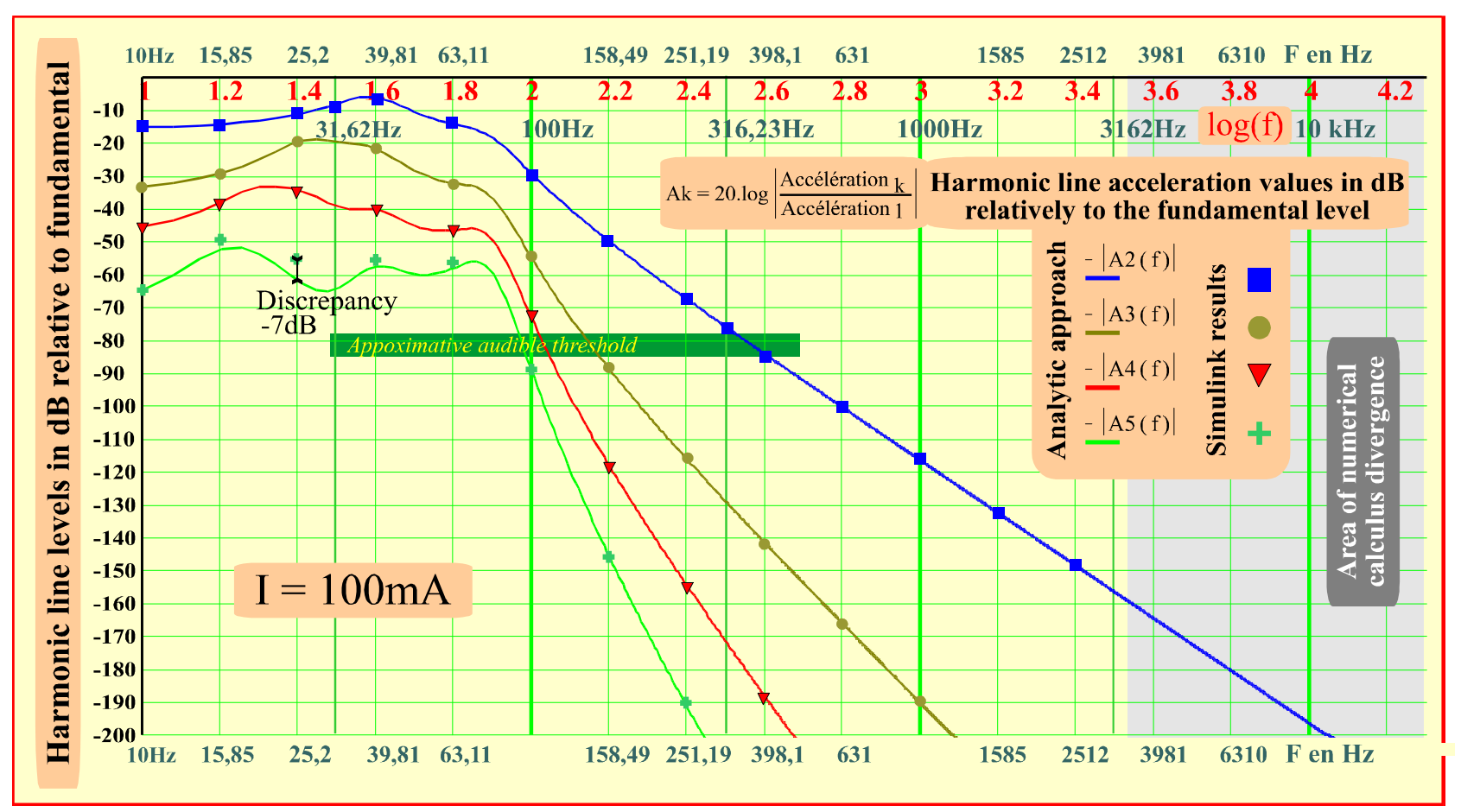

Fig. 6: Behaviour of the first five harmonic components regarding nonlinear stiffness (with $100 \mathrm{~mA}$ )

Hence, in order to fathom about the degree of prospective discrepancy to be expected, an other case is investigated with a significantly increased current value, now fixed at $250 \mathrm{~mA}$. Then, relevant results are plotted and made clear in Fig.7. Since the purpose of this illustration is only to detect eventual flaws of the analytic model, fundamental level values are not given (being considered useless in this case). 


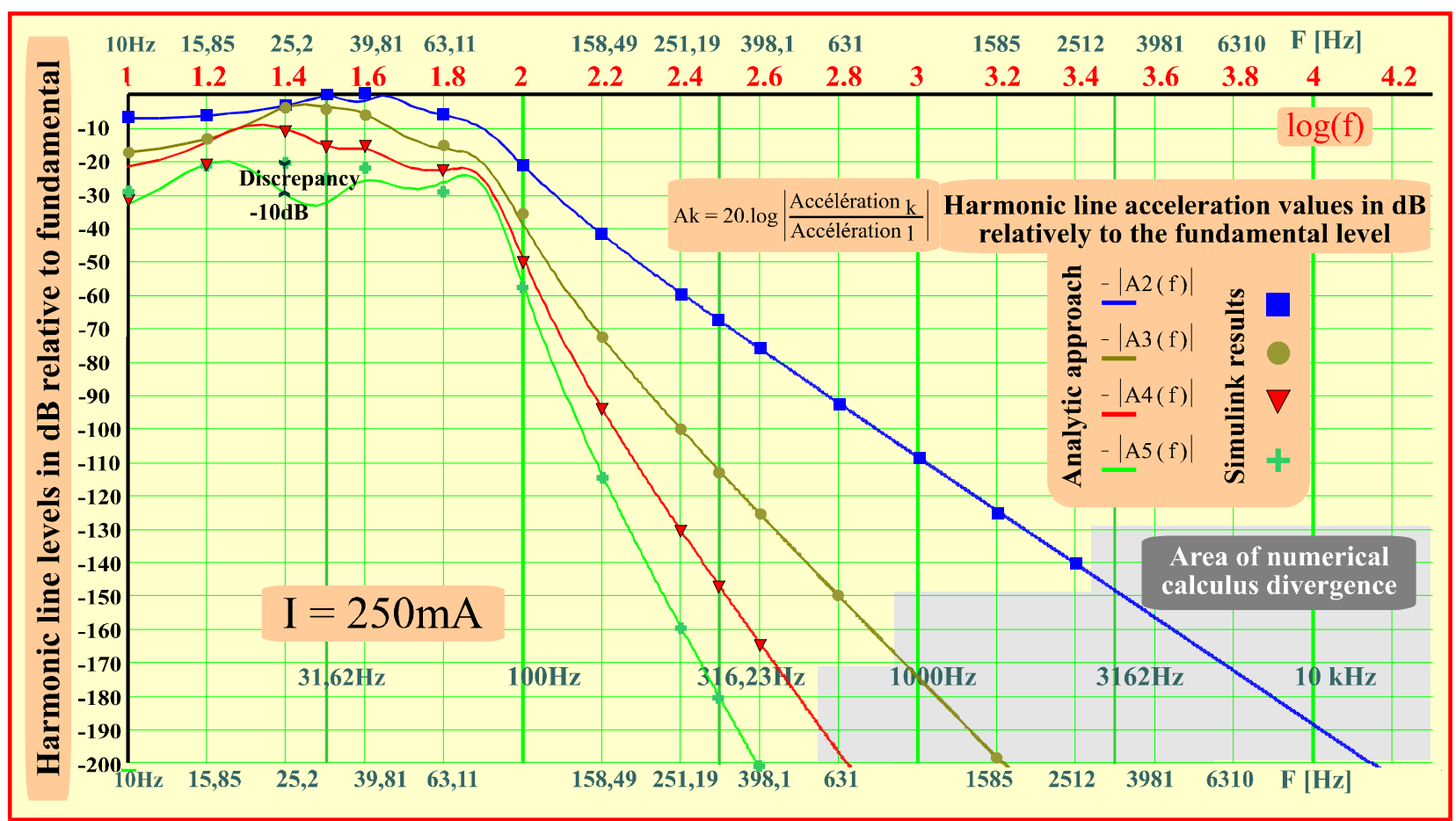

Fig. 7: Behaviour of the first five harmonic lines regarding nonlinear stiffness (with $250 \mathrm{~mA}$ )

Considering now Fig.7, as the driving current is significantly increased several noticeable discrepancies show up at low frequency values as regard both fourth and fifth harmonic components, with local inaccuracies reaching up to $10 \mathrm{~dB}$. However, on the whole the analytic approach behaves properly and most especially as the frequency is increased.

\section{IMPROVING THE HARMONIC LINES REPRESENTATION}

In the first part of this paper, the classical way that hinges on taking the fundamental level as a reference has been used with the only purpose of comparison between numerical and analytic results. However, such a practice proves unsuitable for understanding the relative influence of the sources of distortion. Then, in the following we take as reference the acceleration level of the gravity constant $\left(9.81 \mathrm{~m} / \mathrm{s}^{2}\right)$ as is classical in many a technical field of physics. As a first consequence one can assess the relative importance of the former cases that can be compared.

\subsection{Investigating on the relative influence of the harmonic two}

As an illustration, we consider the former distortion cases (with a $100 \mathrm{~mA}$ current driving) associated with the second harmonic components. Then, the effects respectively due to the force factor, the stiffness and the solenoid interaction, can be plotted while considering the gravity constant as the acceleration reference value. Results are depicted in Fig.8, while taking account of the reference transducer data [10]. 


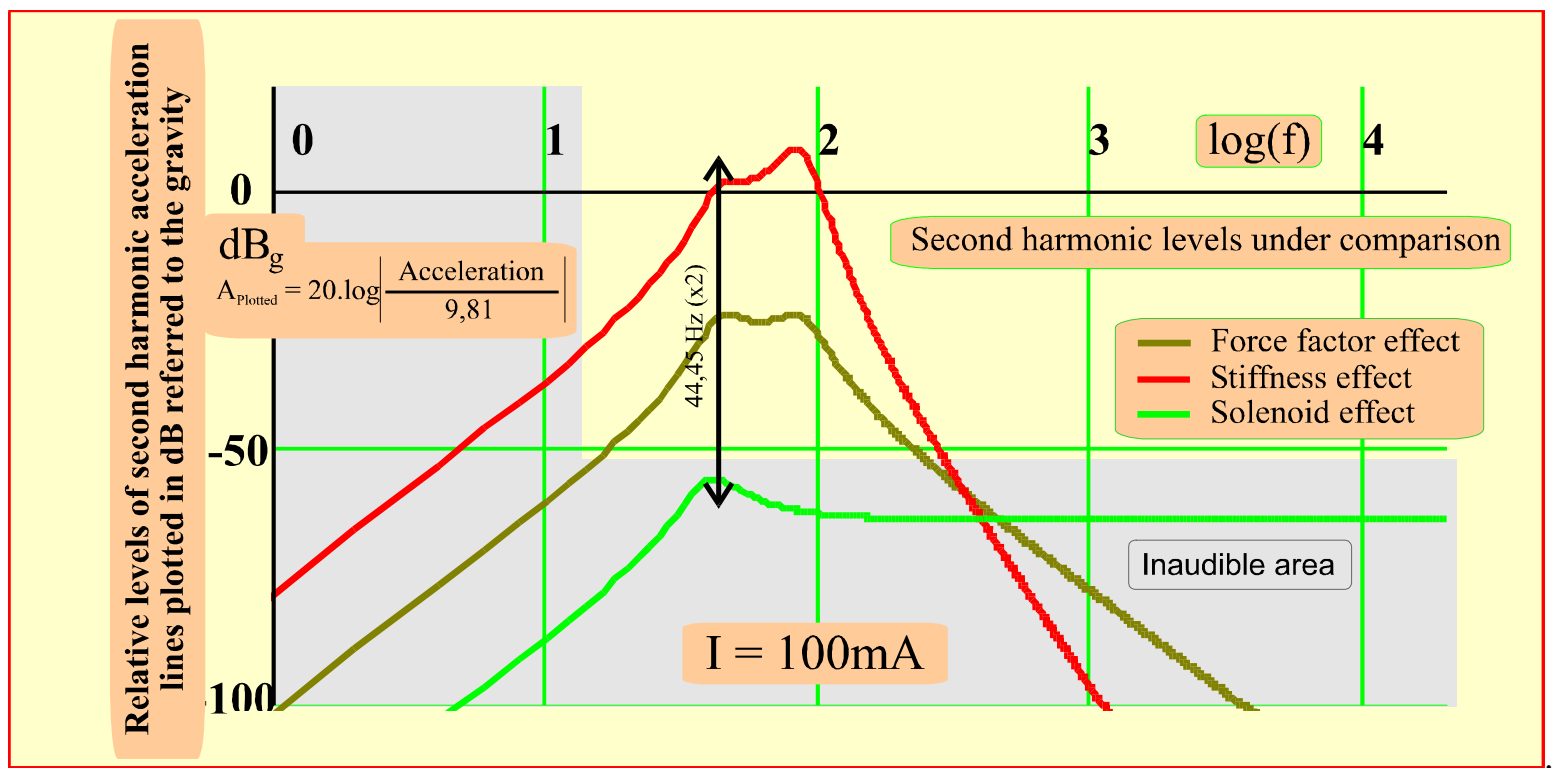

Fig. 8: Comparison between the relative effects of the second harmonic distortion lines

Straightforward acoustic considerations [1,6] allow to highlight the audible threshold with the following equivalence $\left[0 \mathrm{~dB}_{\mathrm{SL}} \Leftrightarrow-51 \mathrm{~dB}_{\mathrm{g}}\right.$ ]. It is clear from Fig.8 that with such a low $100 \mathrm{~mA}$ current value the solenoid effect is negligible while the force factor effect is predominant at low frequencies. Then, although unusual in the state of the art, taking the choice of a given acceleration value as a reference improves the understanding of the relative effects.

\section{INVESTIGATING ON THE HARMONIC DISTORTION DUE TO THE DRAG FORCE}

The mechanical resistance of driver suspension losses can be investigated with a view to designing specific metrological devices. Although the transducer considered for the illustration is not fitted for such a metrological purpose, it is of interest to assume the behaviour of its $f_{\mathrm{m}}$ parameter as a nonlinear function of the speed of the diaphragm (v) and to determine the entailed distortion effect. To our knowledge such an investigation is in no way a classical approach described in the literature.

\subsection{A simple law accounting for the Drag force}

At first a general power-series function of speed can be considered to describe the mechanical damping parameter and drag force as follows:

$$
f_{m(v)}=f_{0}+f_{1} \cdot v+f_{2} \cdot v^{2}+f_{3} \cdot v^{3}+f_{4} \cdot v^{4}+f_{5} \cdot v^{5}+\varepsilon
$$

Although devoid of physical meaning, such a writing could be assessed with a speed observed at steady state. Then, considering back the physical meaning the coefficient $f_{1}$ is a rather insignificant quantity, just allowing for some sort of unsymmetrical interaction that we shall neglect in the following illustration. Conversely, $f_{2}$ is the prominent factor taking account of the drag force that is clearly a function of the volumetric mass $(\rho)$ of the fluid flowing around the transducer. Then with a clear physical meaning, Eq.28 could be written as:

$$
\boldsymbol{f}_{m(v)}=\boldsymbol{f}_{0}+\boldsymbol{f}_{2} \cdot \boldsymbol{v}^{2}+\varepsilon \quad \text { with } \boldsymbol{f}_{2} \cdot \boldsymbol{v}^{2}=\mathrm{C}_{\mathrm{x}} \cdot S \cdot \frac{1}{2} \cdot \rho \cdot \boldsymbol{v}^{2} \quad[\mathrm{~N} /(\mathbf{m} / \mathbf{s})]
$$

In such a relation, $\mathrm{C}_{\mathrm{x}}$ is a classical drag coefficient that we will take as the unity, and $S$ the active surface of the diaphragm $\left(57 \mathrm{~cm}^{2}\right.$ for the EM 428 transducer). Hence a general analytic rationale can be developed.

\subsection{Harmonic components of displacement due to Drag force}

At first let's consider the auxiliary quantities $Y$ and $Y_{\mathrm{i}}$ defined with:

$$
Y_{\mathrm{i}}=X_{1} \quad Y_{2}=2 . X_{2} \quad Y_{3}=3 . X_{3} \quad Y_{4}=4 . X_{4} \quad Y_{5}=5 . X_{5}
$$




$$
Y=Y_{1} \cdot e^{1 \cdot \psi}+Y_{2} \cdot e^{2 \cdot \psi}+Y_{3} \cdot e^{3 . \psi}+Y_{4} \cdot e^{4 \cdot \psi}+Y_{5} \cdot e^{5 \cdot \psi}+\mathcal{E}
$$

Then, as regards speed we have:

$$
\dot{X}=j \omega Y \text {,with: } \dot{X}^{2}=-\omega^{2} \cdot Y^{2}, \dot{X}^{3}=-j \omega^{3} \cdot Y^{3}, \dot{X}^{4}=\omega^{4} \cdot Y^{4}, \dot{X}^{5}=j \omega^{5} \cdot Y^{5}
$$

On the other hand, the $f_{\mathrm{m}}$ coefficient against displacement and successive derivatives is such as:

$$
f_{m(X)}=\frac{1}{2^{0}} \cdot f_{0}+\frac{1}{2^{1}} \cdot f_{1} \cdot \dot{X}+\frac{1}{2^{2}} \cdot f_{2} \cdot \dot{X}^{2}+\frac{1}{2^{3}} \cdot f_{3} \cdot \dot{X}^{3}+\frac{1}{2^{4}} \cdot f_{4} \cdot \dot{X}^{4}+\frac{1}{2^{5}} \cdot f_{5} \cdot \dot{X}^{5}+\varepsilon
$$

With a driving current noted $\boldsymbol{i}=\boldsymbol{i}_{0} \cdot \mathrm{e}^{\mathrm{j} \omega \mathrm{t}}=\boldsymbol{i}_{0} \cdot \mathrm{e}^{\boldsymbol{\psi}}$, the relevant part of $\mathbf{E q . 1}$ can be formulated as:

$$
\begin{aligned}
B_{1} \cdot \mathrm{i}_{0} \cdot e^{1 \cdot \psi}=- & M_{m} \cdot \omega^{2} \cdot\left[X_{1} \cdot e^{1 \cdot \psi}+4 X_{2} \cdot e^{2 \cdot \psi}+9 X_{3} \cdot e^{3 \cdot \psi}+16 X_{4} \cdot e^{4 \cdot \psi}+25 X_{5} \cdot e^{5 \cdot \psi}+\varepsilon\right] \\
& +k \cdot\left[X_{1} \cdot e^{1 \cdot \psi}+X_{2} \cdot e^{2 \cdot \psi}+X_{3} \cdot e^{3 \cdot \psi}+X_{4} \cdot e^{4 \cdot \psi}+X_{5} \cdot e^{5 \cdot \psi}+\varepsilon\right] \\
& +j \cdot \omega \cdot f^{\prime} \cdot \cdot\left[X_{1} \cdot e^{1 \cdot \psi}+2 X_{2} \cdot e^{2 \cdot \psi}+3 X_{3} \cdot e^{3 \cdot \psi}+4 X_{4} \cdot e^{4 \cdot \psi}+5 X_{5} \cdot e^{5 \cdot \psi}+\varepsilon\right] \\
& -\omega^{2} f^{\prime} \cdot \cdot\left[X_{1}^{2} \cdot e^{2 \cdot \psi}+2 X_{1} Y_{2} \cdot e^{3 \cdot \psi}+\left(Y_{2}^{2}+2 X_{1} \cdot Y_{3}\right) \cdot e^{4 \cdot \psi}+\left(X_{1} \cdot Y_{4}+2 X_{2} \cdot Y_{3}\right) \cdot e^{5 \cdot \psi}+\varepsilon\right] \\
& -j \omega^{3} f^{\prime}{ }_{2} \cdot\left[X_{1}^{3} \cdot e^{3 \cdot \psi}+3 X_{1}^{2} Y_{2} \cdot e^{4 \cdot \psi}+\left(2 X_{1}^{2} \cdot Y_{3}+3 X_{1} \cdot Y_{2}^{2}\right) \cdot e^{5 \cdot \psi}+\varepsilon\right] \\
& +\omega^{4} f^{\prime}{ }_{3} \cdot\left[X_{1}^{4} \cdot e^{4 \cdot \psi}+4 X_{1}^{3} Y_{2} \cdot e^{5 \cdot \psi}+\varepsilon\right] \\
& +j \omega^{5} f^{\prime}{ }_{4}^{\prime} \cdot\left[X_{1}^{5} \cdot e^{5 \cdot \psi}+\varepsilon\right]
\end{aligned}
$$

In this writing the auxiliary parameters $\boldsymbol{f}_{\mathrm{i}}=\left(1 / 2^{\mathrm{i}}\right) \cdot f_{\mathrm{i}}$ allow a simplified notation. Moreover, as before while considering the quantities arranged in Table $\mathbf{I}$, we have the following identifications:

$$
\begin{aligned}
& \boldsymbol{M}_{\mathrm{m}} \cdot \mathbf{X}_{\mathbf{1}} \cdot \mathbf{P}_{\mathbf{1}}=\boldsymbol{B}_{1} \cdot \mathbf{i}_{\mathbf{0}} \quad \text { [fundamental frequency] } \\
& M_{\mathrm{m}} \cdot \mathrm{X}_{2} \cdot \mathrm{P}_{2}=\left[f^{\prime} \cdot \omega^{2} \cdot \mathrm{X}_{1}{ }^{2}\right] \\
& M_{\mathrm{m}} \cdot \mathrm{X}_{3} \cdot \mathrm{P}_{3}=\left[f^{{ }^{\prime}} \cdot \omega^{2} \cdot 2 \cdot \mathrm{X}_{1} \cdot \mathrm{Y}_{2}+f^{\prime} \cdot j \omega^{3} \cdot \mathrm{X}_{1}{ }^{3}\right] \\
& M_{\mathrm{m}} \cdot \mathrm{X}_{4} \cdot \mathrm{P}_{4}=\left[f^{\prime}{ }_{1} \cdot \omega^{2} \cdot\left(\mathrm{Y}_{2}{ }^{2}+2 \cdot \mathrm{X}_{1} \cdot \mathrm{Y}_{3}\right)+f^{\prime} \cdot j \omega^{3} \cdot\left(3 \cdot \mathrm{X}_{1}{ }^{2} \cdot \mathrm{Y}_{2}\right)-f^{3} \cdot \omega^{4} \cdot \mathrm{X}_{1}{ }^{4}\right] \\
& M_{\mathrm{m}} \cdot \mathrm{X}_{5} \cdot \mathrm{P}_{5}=\left[f^{\prime}{ }_{1} \cdot \omega^{2} \cdot\left(\mathrm{X}_{1} \cdot \mathrm{Y}_{4}+2 \mathrm{Y}_{2} \cdot \mathrm{Y}_{3}\right)+f^{\prime}{ }_{2} \cdot j \omega^{3} \cdot\left(2 \cdot \mathrm{X}_{1}{ }^{2} \cdot \mathrm{Y}_{3}+3 \cdot \mathrm{X}_{1} \cdot \mathrm{Y}_{2}{ }^{2}\right)-f_{3}{ }_{3} \cdot \omega^{4} \cdot 4 \cdot \mathrm{X}_{1}{ }^{3} \cdot \mathrm{Y}_{2}-f_{4} \cdot j \omega^{5} \cdot \mathrm{X}_{1}{ }^{5}\right]
\end{aligned}
$$

As regards Eq.24. in the same way as the prior analysis (relative to $\boldsymbol{k}_{\mathrm{m}}$ ), such a writing may be reformulated as the following set of relations:

$$
\begin{aligned}
& \mathbf{X}_{1}=\mathbf{F}_{1} \cdot[\varphi] \quad \text { [fundamental frequency] } \\
& \mathbf{X}_{2}=\mathbf{F}_{2} \cdot\left[\mathbf{h}_{1} \cdot \omega^{2} \cdot \mathbf{X}_{1}^{2}\right] \\
& \mathbf{X}_{3}=F_{3} \cdot\left[h_{1} \cdot \omega^{2} \cdot 4 \cdot X_{1} \cdot X_{2}+j \cdot \omega^{3} \cdot h_{2} \cdot X_{1}{ }^{3}\right] \\
& X_{4}=F_{4} \cdot\left[h_{1} \cdot \omega^{2} \cdot\left(4 \cdot X_{2}{ }^{2}+6 \cdot X_{1} \cdot X_{3}\right)+j \cdot \omega^{3} \cdot h_{2} \cdot 6 \cdot X_{1}{ }^{2} \cdot X_{2} \quad-h_{3} \cdot \omega^{4} \cdot X_{1}^{4}\right] \\
& X_{5}=F_{5} \cdot\left[h_{1} \cdot \omega^{2} \cdot\left(4 \cdot X_{1} \cdot X_{4}+12 \cdot X_{2} \cdot X_{3}\right)+j \cdot \omega^{3} \cdot h_{2} \cdot\left(6 X_{1}^{2} \cdot X_{3}+12 \cdot X_{1} \cdot X_{2}^{2}\right)-h_{3} \cdot \omega^{4} \cdot 8 \cdot X_{1}^{3} \cdot X_{2}-h_{4} \cdot j \omega^{5} \cdot X_{1}{ }^{5}\right] \text {, }
\end{aligned}
$$

with auxiliary parameters defined as: $\mathrm{h}_{i}=\frac{f_{i}}{2^{i}} \cdot \frac{1}{M_{m}}$

Hence, here again each component can be expressed on its own, with for instance the first four components explicitly given with:

$$
\begin{aligned}
& X_{1}=F_{1} \cdot[\varphi] \quad[\text { fundamental frequency }] \\
& X_{2}=F_{1}{ }^{2} \cdot \mathbf{F}_{2} \cdot \varphi^{2} \cdot \omega^{2} \cdot\left[\mathbf{h}_{1}\right] \\
& X_{3}=F_{1}{ }^{3} \cdot \mathbf{F}_{3} \cdot \varphi^{3} \cdot \omega^{3} \cdot\left[\mathbf{F}_{2} \cdot \mathbf{4} \cdot \omega^{2} \cdot \mathbf{h}_{1}+j \cdot \mathbf{h}_{2}\right] \\
& \mathbf{X}_{4}=\mathbf{F}_{1}{ }^{4} \cdot \mathbf{F}_{4} \cdot \varphi^{4} \cdot \omega^{4} \cdot\left[\mathbf{4} \cdot \mathbf{F}_{2}{ }^{2} \cdot \omega^{2} \cdot \mathbf{h}_{1}{ }^{3}+\mathbf{2 4} \cdot \mathbf{F}_{2} \cdot \mathbf{F}_{3} \cdot \omega^{2} \cdot \mathbf{h}_{1}{ }^{2}+\mathbf{6} \cdot \mathbf{j} \omega \cdot \mathbf{h}_{1} \cdot \mathbf{h}_{2} \cdot\left(\mathbf{F}_{2}+\mathbf{F}_{3}\right)-\mathbf{h}_{3}\right]
\end{aligned}
$$

\subsection{A prospective application}

As a prospective application one could investigate on the volumetric mass that could be measured thanks to a transducer optimized to this end. The mass being a conservative quantity, the static pressure around the transducer could be the quantity under experiment. As an illustration with air, $\boldsymbol{\rho}=1,23 \mathrm{~kg} / \mathrm{m}^{3}$ at the atmospheric pressure, taking $\mathbf{C}_{\mathbf{x}}$ as the unity and $S=57 \mathrm{~cm}^{2}$, as regard Eq.29 and Table III $\left(f_{0}=1,239 \mathrm{~kg} / \mathrm{s}\right)$ 
we have $f_{2}=\left(1 / 2 . \rho \cdot C_{x} \cdot S\right)=3,506.10^{-3} \mathrm{~N} /(\mathbf{m} / \mathbf{s})^{3}$. Then if the static pressure were to be increased the coefficient $f_{\mathrm{m}}$ would behave according to Fig. 9 .

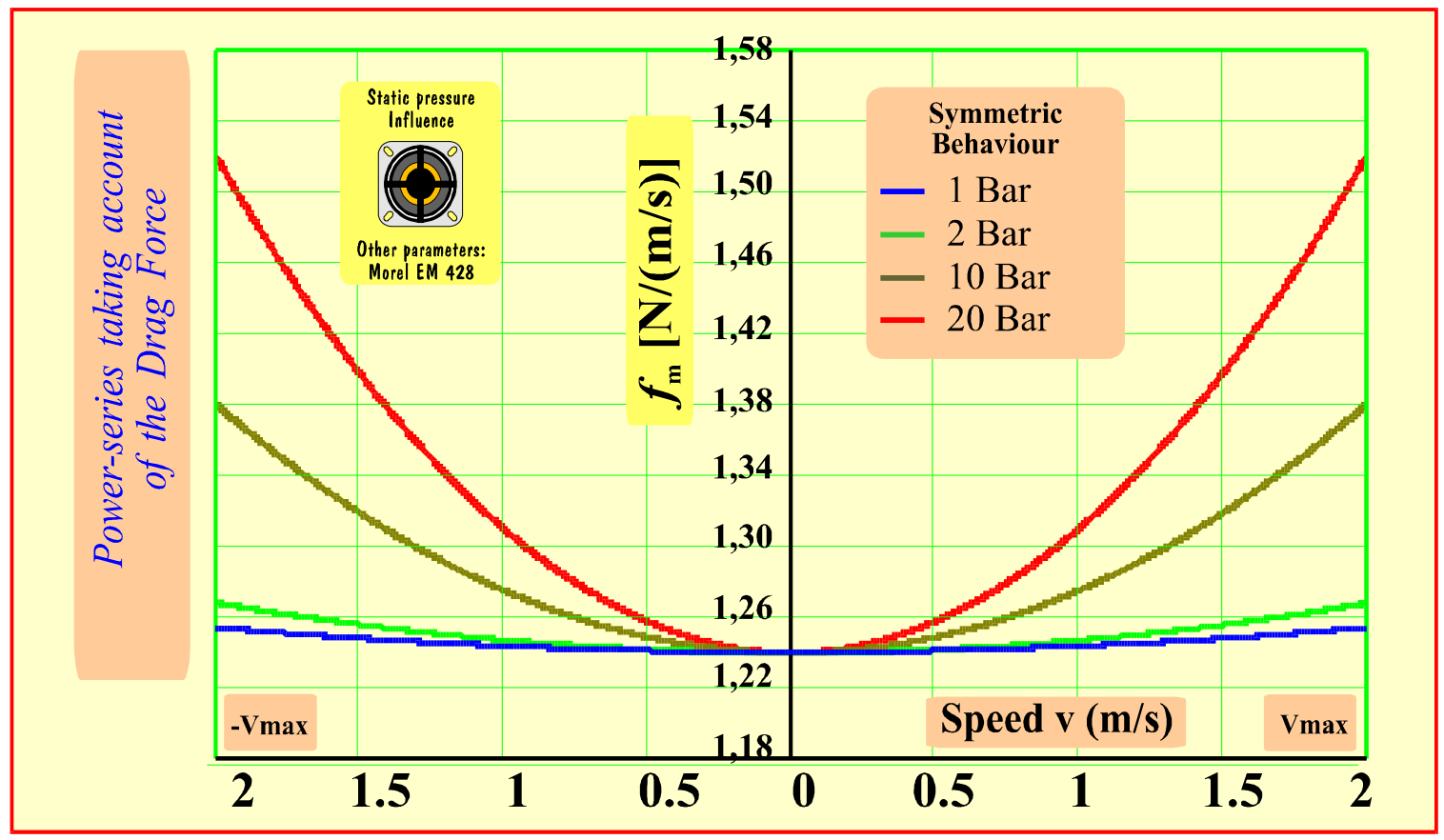

Fig. 9: Influence of the static pressure on the drag force part of the $f_{\mathrm{m}}$ coefficient

\subsubsection{Harmonic components of acceleration due to the Drag force}

With Eq.15 and taking account of the exclusive evenness associated with Eq.29, the set of Eqs.36 yields the three following harmonic components:

$$
\begin{aligned}
& A_{1}=-F_{1} \cdot \varphi \cdot \omega^{2} \\
& A_{3}=-9 . F_{1}{ }^{3} \cdot F_{3} \cdot \varphi^{3} \cdot j \cdot \omega^{5} \cdot h_{2} \\
& A_{5}=150 \cdot F_{1}{ }^{6} \cdot F_{3} \cdot F_{5} \cdot \varphi^{5} \cdot \omega^{8} \cdot h_{2}
\end{aligned}
$$

Then, special cases may be investigated involving both this analytic approach and relevant numerical Simulink ${ }^{\circledR}$ computations.

\subsubsection{Comparison between analytical and numerical results}

Considering $\mathbf{h}_{\mathbf{2}}$ given with Eq.36, if $\mathbf{P}_{\mathbf{a}}$ is the atmospheric pressure and $\mathbf{P}$ the pressure experimented with, a given static pressure condition entails:

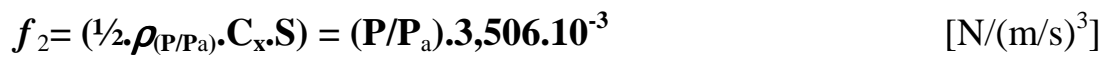

At first, it is clear that the fundamental is devoid of any useful information about the drag force, then about the static pressure. Conversely, according to Eq.39, the characterisation of the third line could be directly indicative of the pressure. Moreover, the sensitivity of a prospective device stemming from such an approach would be directly function of the third power of the current value, insofar as the other shortcomings (generating their part within this third component) would be duly rejected by way of any differential metrological approach in the state of the art [14].

In a first case we take as before a quite low value for the driving current with $100 \mathrm{~mA}$. Moreover the chosen relative static pressure value is also not that much noticeable with only twice the atmospheric pressure as is plotted in green in Fig.9. Then, according to the aforementioned interest about the gravity reference level, analytical and numerical results can be compared and made clear with Fig.10. 


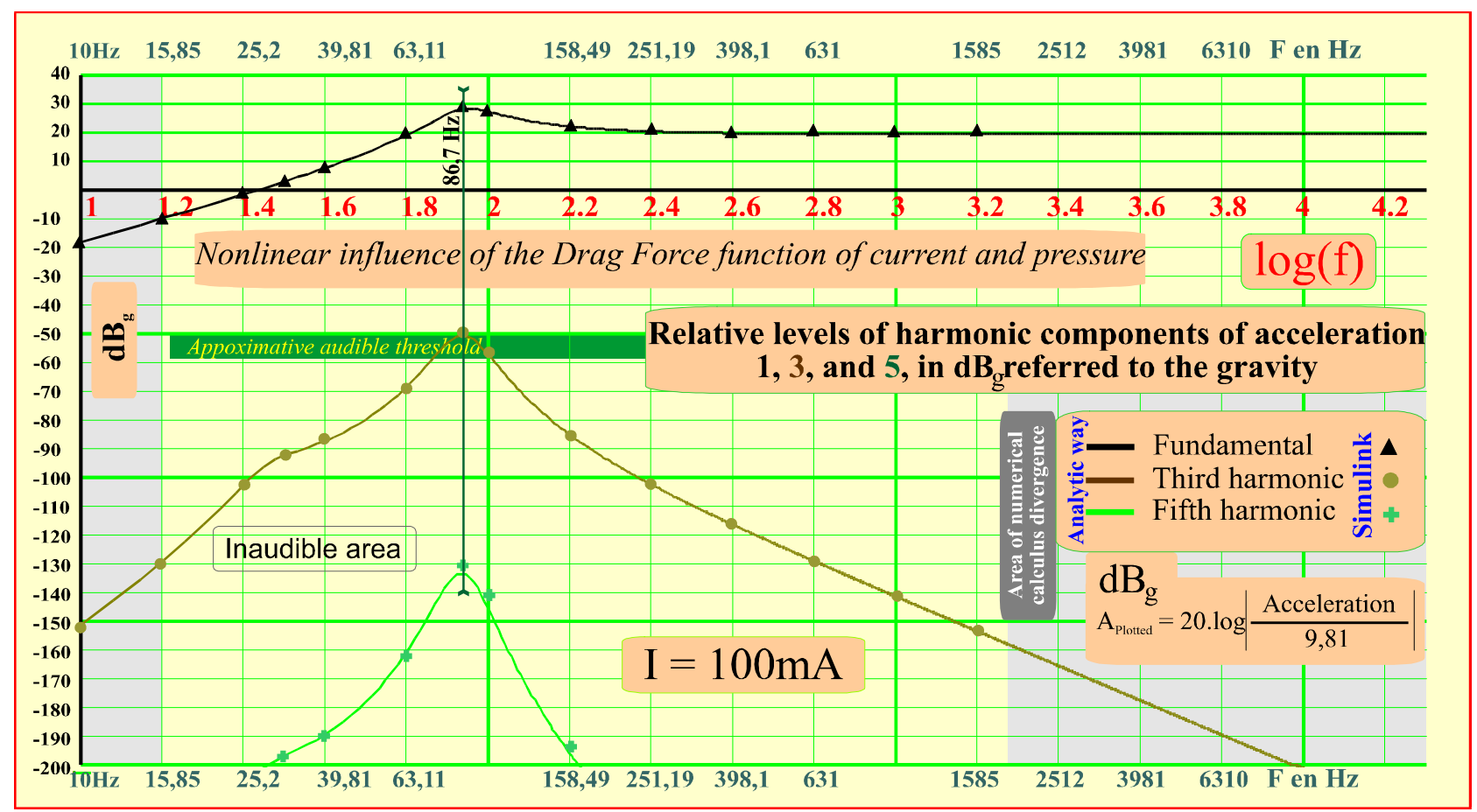

Fig. 10: Influence of the drag force through the third and fifth components $(P=2 \mathrm{bar}, \mathrm{I}=0.1 \mathrm{~A})$

Indeed, the gravity reference way to represent the specific pattern relative to each component is not flawed with the pattern of the fundamental, as is unfortunately the case with the classical way to refer to the level of the latter. Then, Fig.10 allows a genuine observation about the real level featured by the harmonic components. Here the extremum associated with the third component (at the specific frequency $3 \times 86,7 \mathrm{~Hz}$ ) is relevant with the maximum value characterizing the sensitivity of a device whose operation would be fostered by our rationale. Here, with the relatively moderate value of the driving current, the signal would be just close to the audible threshold.

More explicitly, considering the preceding notations together with Eq.39, the third acceleration component analysis may also be stated as the product of a specific metrological constant $\left(\mathbf{K}_{\mathbf{a}}\right)$ by a relevant function of frequency $\left(\Upsilon_{(\omega)}\right)$ so as to highlight the parameter of sensitivity for a dedicated sensor $(\mathbf{S} \quad)\left[\left(\mathrm{m} / \mathrm{s}^{2}\right) /\left(\mathrm{kg} / \mathrm{m}^{3}\right)\right]$.

$$
\mathrm{A}_{3}=-\frac{9}{8} \cdot \frac{B_{l}{ }^{3}}{M_{m}{ }^{4}} \cdot \mathrm{C}_{\mathrm{x}} \cdot \mathrm{S} \cdot\left[j \cdot \omega^{5} \cdot \mathbf{F}_{1}{ }^{3} \cdot \mathbf{F}_{3}\right] \cdot i_{0}^{3} \cdot \rho, \text { or: } \mathbf{A}_{3}=\mathbf{K}_{\mathbf{a}} \cdot \Upsilon_{(\boldsymbol{\omega})} \cdot i_{0}{ }^{3} \cdot \boldsymbol{\rho} \text { or: } \mathbf{A}_{\mathbf{3}}=\mathbf{S} \cdot \boldsymbol{\rho}
$$

Then aside from those technical prospective considerations, it is necessary to get back to the assessment of the analytical approach, with a second case to be investigated with both approaches considering a more significant current value: Here, the current is now set to $250 \mathbf{~ m A}$ while maintaining the static pressure value at twice the atmospheric pressure.

Then, a pertinent comparison between analytical and numerical results is allowed while considering the patterns of the harmonic components depicted in Fig.11. 


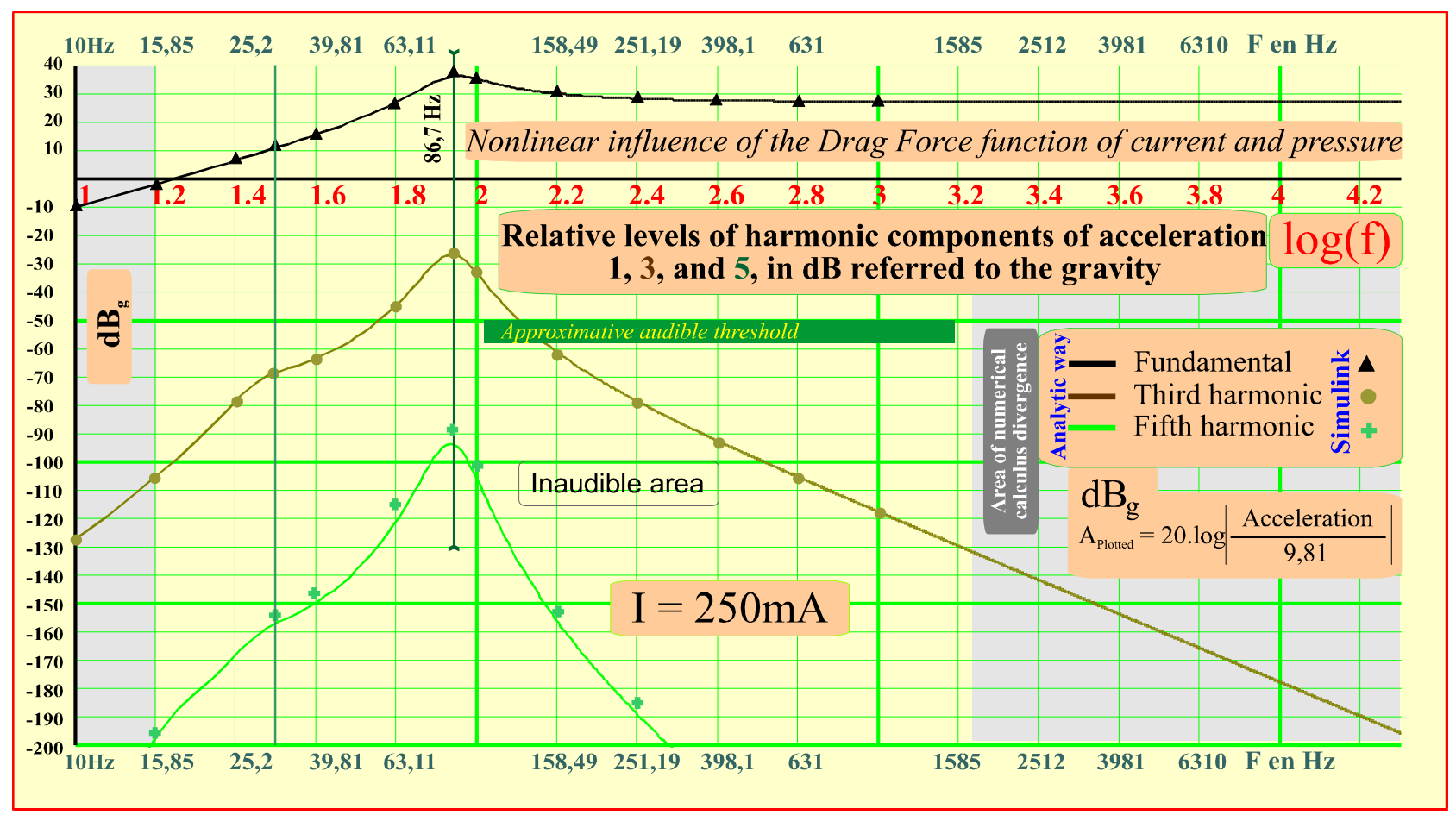

Fig. 11: Influence of the drag force through components 3 and 5 , for a 2 bar static pressure $(0.25 \mathrm{~A})$

As expected, the relevant level of the acceleration signal are noticeably increased with the driving current, suggesting that some degree of freedom would be allowed as regards the design of a specific sensor. In this way it is clear that harmonic components of both third and fifth orders are substantially enhanced.

\section{GETTING AHEAD TO IMPROVE HARMONIC LINES REPRESENTATION}

As a major improvement, taking the gravity as a reference proves to be of help for interpreting the behaviour of harmonic distortion. A second provision may be considered while plotting each component according to its own real (eventually audible) frequency value. Fig.12 translates in this way the data depicted in Fig.4.




Fig. 12: Real behaviour of each harmonic component displayed according to their own frequency in the case of a nonlinear force factor and a $100 \mathrm{~mA}$ driving current

As real frequency values are directly displayed on such a representation, physical properties are made much clearer. At first, whatever the component a maximum shows up at the natural mechanical frequency of the transducer. Then, as a prominent property each harmonic component shows off a second maximum exactly arranged at its own specific place as the product of the fundamental resonance frequency by the considered order of said component. Now, considering the fifth component, as is also clear with Fig. 4., a quite peculiar singularity occurs around the special frequency value $[42.6$ x $5=213 \mathrm{~Hz}]$. Such a "Moot Extremum" point was closely observed with both the analytic and numerical approaches, up to now without any obvious physical meaning nor mathematical justification as regards the set of Eqs.13 [6, 15].

On the other hand, the falling off regarding each harmonic component at high frequencies is easily quantified, at first while perusing the figure, but more precisely with the analytic approach applied on both sides of the decade $[10 \mathrm{kHz}-100 \mathrm{kHz}]$. Then, asymptotic level lessening values, all with a $\mathbf{- 4 0} \mathbf{~ d B}_{\mathbf{g}}$ fall apart from the former one, are characterized as follows:

Fundamental behaviour : invariant level

Asymptotic fall of harmonic component 2: $-40 \mathrm{~dB}_{\mathrm{g}} /$ decade

Asymptotic fall of harmonic component 3: $-80 \mathrm{~dB}_{\mathrm{g}} /$ decade

Asymptotic fall of harmonic component 4: $-120 \mathrm{~dB}_{\mathrm{g}} /$ decade

Asymptotic fall of harmonic component 5: $-160 \mathrm{~dB}_{\mathrm{g}} /$ decade

Asymptotic fall of harmonic component 6: $-200 \mathrm{~dB}_{\mathrm{g}} /$ decade

As an a priori non obvious property only limited to the harmonic components investigation (since it would be false with a study on intermodulation generation), the set of Eq.13 clearly indicates that any given alteration regarding a component noted $\mathbf{n}$, (due to a given change of relevant coefficient), should not interact with any former component (n-1 for instance).

Furthermore the way to display each component against its own frequency confirms its interest when considering the abovementioned Fig.6 associated with the stiffness analysis. Expanding each frequency scale as before, Fig.13 can be considered with a view to getting specific conclusions and understanding about the effective behaviour of the system.

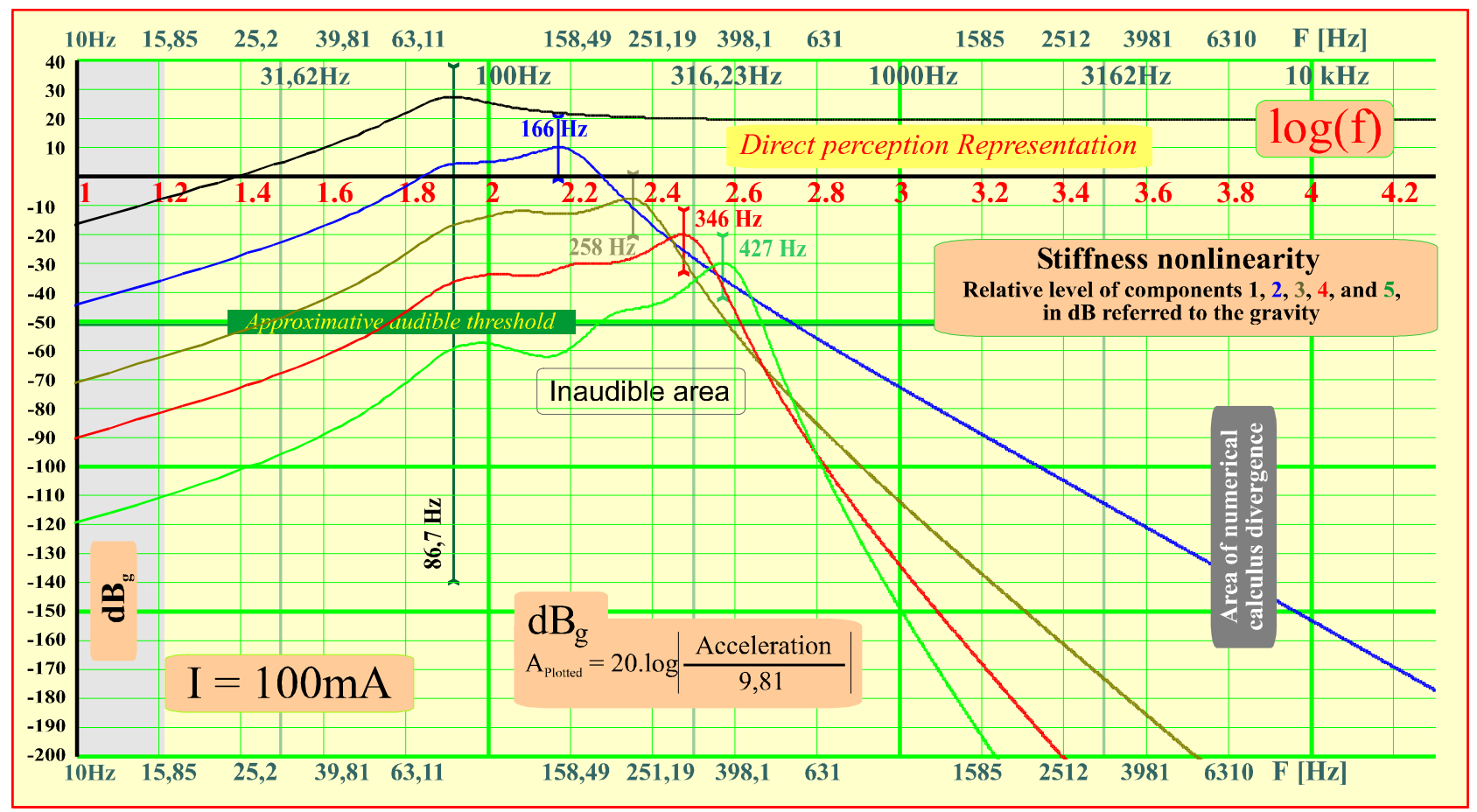

Fig. 13: Behaviour of each harmonic component displayed according to its own frequency in the case of a nonlinear stiffness parameter and a $100 \mathrm{~mA}$ driving current 
As in the former case, all components display a first maximum at the fundamental mechanical frequency of the transducer. Again, each harmonic component is fitted with a second maximum exactly arranged at its own specific place as aforementioned.

As a major difference when compared with the force factor investigation, here the level abatement while increasing frequency is quite more marked although with the same property $(-\mathbf{4 0} \mathbf{d B} \mathbf{g}$ fall marking one apart from the former one). Hence we have:

Fundamental behaviour : invariant level

Asymptotic fall of harmonic component 2: $-80 \mathrm{~dB}_{\mathrm{g}} /$ decade

Asymptotic fall of harmonic component 3: $-120 \mathrm{~dB}_{\mathrm{g}} /$ decade

Asymptotic fall of harmonic component 4: $-160 \mathrm{~dB}_{\mathrm{g}} /$ decade

Asymptotic fall of harmonic component 5: $-200 \mathrm{~dB}_{\mathrm{g}} /$ decade

Such a behaviour discrepancy is quite naturally explained while considering the shift order stemming from the left member of Eq.10 (while multiplying by the current) as regards the analysis of the force factor.

\section{SPECIAL BEHAVIOUR WHILE INVESTIGATING ON A PARAMETER EVENNESS}

Considering now the constitutive coefficient involved within the power-series relative to the nonlinear parameters, even and odd parts can be isolated according to the straightforward following relation standing for Eq.4:

$$
\lambda(x)=\lambda_{0}+\sum_{i=1}^{n} \lambda_{i} \cdot x^{i}=\left[\lambda_{0}+\sum_{i=1}^{n / 2} \lambda_{2 \cdot i} \cdot x^{2 \cdot i}\right]+\left[\sum_{i=1}^{n / 2} \lambda_{2 \cdot i-1} \cdot x^{2 \cdot i-1}\right]=\lambda_{\text {even }}(x)+\lambda_{\text {odd }}(x)
$$

Then, a most interesting point can be underlined if we artificially consider only the even part of such a parameter. As regards the force factor $\mathbf{B}_{1}$ and the former representation given in Fig.12, zeroing the odd coefficients with $\mathbf{b}_{1}=\mathbf{b}_{3}=\mathbf{b}_{5}=\mathbf{0}$ in Table II, entails the results depicted in Fig. 14.

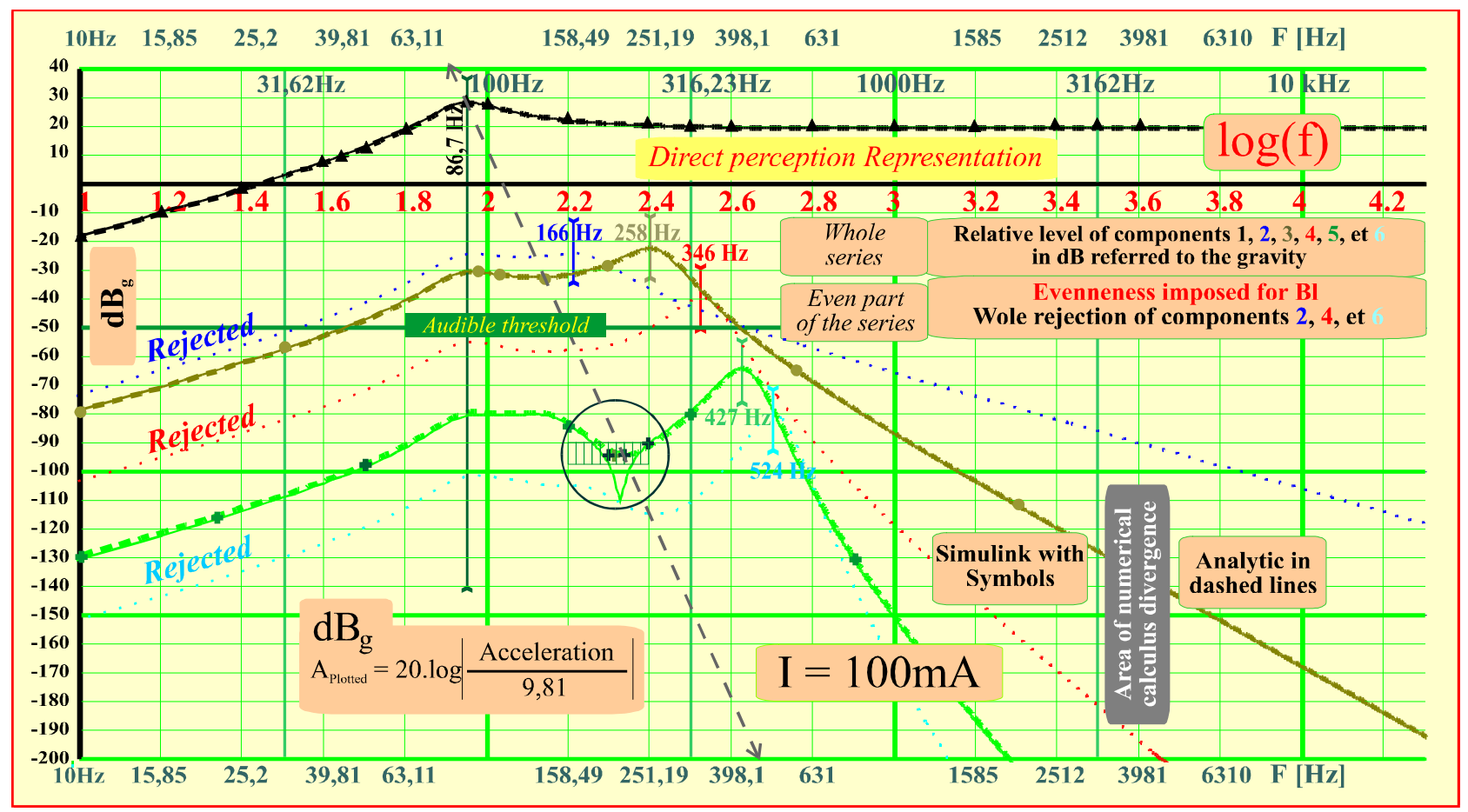

Fig. 14: Calculated behaviour of the harmonic components displayed according to their own frequency in the case of an evened nonlinear force factor and a $100 \mathrm{~mA}$ driving current

Dashed line are the result of the analytic approach while same symbols as those used before are representative of the numerical results. It is clear from Fig.14 that the even components, 2, 4, and 6, (still represented in dotted lines for the purpose of comparison), are totally rejected. 
Another most noticeable point concerns the abovementioned "Moot Extremum" point associated with the second order discontinuity that was assigned to the fifth component. Then, zeroing the odd coefficients made this point disappear as a sharp discontinuity, being now replaced by a smooth minimum. So as to check upon it, other numerical computations (still operated with Simulink ${ }^{\circledR}$ ) were carried out for this point together with an apt set of other ones closely arranged around it: As a result, both analytic and numeric approaches brought evidence about this major change in the pattern of this component. Moreover, after trying the respective effects of selectively zeroing coefficients $\mathbf{b}_{\mathbf{1}}$ and $\mathbf{b}_{\mathbf{3}}$, the smoothing change proved to be clearly attributed only to $\mathbf{b}_{\mathbf{1}}$. At this point, Fig.14 displayed without such a discontinuity makes clear a trough-like set of minima highlighted with a falling off dashed line.

Since in no way experimental measurements (and especially thermal ones) are up to now available, we can only assume that the whole physical meaning could be probably explained by way of a minimum entropy generation as the driven system with its electromagnetic energy storage properties generates its harmonic lines $[16,17,18]$. Then, thanks to the thermal know-how of the laboratory this hypothesis will be investigated in the future of this work.

\section{CONCLUSION}

This paper has presented a simple analytic approach allowing to investigate on the harmonic distortion of electrodynamic loudspeakers. As a prominent advantage such an approach allows a quick representation of the components as regards analysis up to the fifth one. The approach is concomitantly supported with numerical computations carried out with a Simulink ${ }^{\circledR}$ model. For the purpose of comparison the measured parameters of a midrange generic transducer have been chosen. Although slight discrepancies may appear, the analytic approach proved to be valuable. Moreover it allows us to analyse the evenness property of a given influence parameter, and an example has been discussed with the force factor. On the other hand, the approach proved to be able to account for nonlinear parameters function of the speed of the diaphragm. Then, as a prospective investigation a metrological application is given as regards the drag force measurement and any parameter relevant with it.

As a noticeable point we have also shown the interest to figure out the acceleration results linked to the entailed audio reproduction, as referred to the gravity constant. Moreover, by way of expanding the display of each component to its real perceived frequency, we have highlighted a specific characteristic as regard two observable distinct maxima respectively occurring: for the first, at the natural mechanical frequency of the fundamental, and for the second one, showing off at the same value times the order of the considered component. We expect to provide an articulate energetical interpretation of such component patterns in the next coming future.

\section{ACKNOWLEDGMENT}

The authors would like to thank Michel Bruneau (Professor Emeritus) for all the most valuable and fruitful discussions we had all along this work. His full-fledged experience in the field of acoustics and genuine kindness have been most contributing to improve the quality of this paper. The authors wish to thank Romain Raveau (Whylot enterprise) for permission to publish the technical aspects of this study.

\section{PATENT PROTECTION POLICY}

The authors would like to point out that after legal registration several aspects dealt with in this work are the subject of a FR patent application.

\section{REFERENCES}

1] R. Lehmann, "Les transducteurs électro et mécano-acoustiques, haut-parleurs et microphones", préface de P. Chavasse, Ed. CHIRON, 1963.

2] P.G.L. Mills \& M.O.J Hawksford, "Distortion Reduction in Moving-Coil Loudspeaker Systems Using Current-Drive technology", J. Audio Eng. Soc. Vol.37, No.3, 1989 March.

3] E. Meriläinen, "Current-Driving of Loudspeakers", Copyright ® Esa T. Meriläinen, Print-on-demand service, www.current-drive.info, USA, 2010, ISBN 1450544009. 
4] A.J.M. Kaiser, "Modelling of the Nonlinear Response of an Electrodynamic Loudspeaker by a Volterra Series Expansion”, J. Audio Eng. Soc., Vol. 35, No.6, 1987 June.

5] W. Klippel, "Dynamic measurement and interpretation of nonlinear parameters of electrodynamic loudspeakers,” J. Audio Eng. Soc., vol. 38, pp. 944-955, 1990.

6] M. Erza, "Contribution à l'étude des non-linéarités au sein d'une association amplificateur-transducteur - Atténuation des distorsions par un mode de contrôle en courant", Ph.D. thesis, Université du Maine, LAUM CNRS-UMR 6613, 22 Novembre 2013.

7] H.D. Harwood, "Loudspeaker Distortion Associated with Low-Frequency Signals", J. Audio Eng. Soc., vol. 20, pp. 718-728, 1972 Nov.

8] A. Dobrucki and C. Szmal, "Nonlinear Distortion of Woofers in the Fundamental Resonance Region", J. Audio Eng. Soc., (Abstracts) vol. 34, p. 389, 1986 May.

9] R.A. Greiner and T.M. Sims, Jr., "Loudspeaker Distortion Reduction", J. Audio Eng. Soc., vol. 32, pp. 956-963, 1984 Dec.

10] Web site MOREL EM 428: http://www.moreleurope.com/data/mediablocks/EM428.pdf

11] Klippel GmbH, "Specification on the KLIPPEL Analyser System", 2005, www.klippel.de

12] H. Jeffreys, B.S. Jeffreys, "Methods of Mathematical Physics", Third edition, Cambridge Mathematical Library, 1972, ISBN 0521664020.

13] W. Klippel, "Tutorial :Loudspeaker nonlinearities - cause, parameters, symptoms", J. Audio Eng. Soc., vol. 54, pp. 907-939, 2006.

14] E. Gaviot, G. Failleau, L. Camberlein, F. Polet, R. Morice, B. Bêche, "Metrological prospects for the assessment of transition plateaus", I.O.P Metrologia, 47, 349-356, 2010.

15] E. Kreyszig, "Advanced Engineering Mathematics", $8^{\text {th }}$ Ed. John Wiley \& Sons. Inc., New York, 2004, ISBN 0-471-33328-X.

16] Prigogine I., "From Being to Becoming: Time and Complexity in the Physical Sciences", 1982, Ed. Masson (French Ed. ISBN 2-225-77924-4), Paris.

17] E. Gaviot, G. Failleau, L. Camberlein, F. Polet, R. Morice, B. Bêche, "Towards a thermodynamic assessment of transition plateaus", I.O.P Metrologia, 47, 357-362, 2010.

18] J. La Salle, S. Lefschetz, "Stability by Liapunov Direct Method", 1961, Ed. Academic Press inc, New York.

\section{APPENDIX}

The transfer function from drive voltage to displacement shows off a natural electrical damping on the Q factor of the system under operation. Then, doubts cast upon the efficiency of the current-drive policy are most often based just on the lack of such natural damping usually entailing an oversized Q that results as a consequence $[3,6]$. In other words, low damping factors associated with current-drive are a crucial problem and are probably the major reason why current drive is still not adopted by the industry. However, effective solutions based on active and passive processing as well as driver and enclosure techniques may be considered as an alternative to the natural filtering of current brought about by the motional impedance. Moreover, operative filtering schemes can be properly operated (and even quite enhanced, insofar as the resonance drift may be compensated against temperature).

As a fundamental requisite the Thévenin impedance seen by the driver (due to the amplifier and passive circuits) has to remain close to infinity (Norton source). Then, one has to discard any solution involving circuit arms connected directly in parallel with the driver, that could untowardly lower the impedance in a given part of the spectrum.

A simple generic scheme is depicted in Fig.15 with a view to rejecting the mechanical resonance while subjecting the voltage to current conditioner to an optimized transconductance function. 


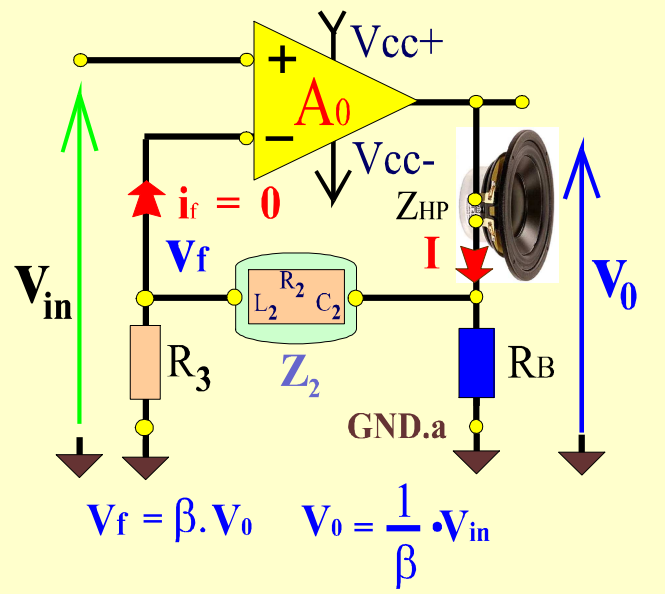

$$
\mathscr{R}=\mathrm{RB} / /\left(\mathrm{Z}_{2}+\mathrm{R}_{3}\right) \quad \mathrm{V}_{\mathbf{0}}=\frac{\left(\mathrm{Z}_{\mathrm{HP}}+\mathscr{R}\right) \cdot\left(\mathrm{Z}_{2}+\mathrm{R}_{3}\right)}{\mathscr{R} \cdot \mathrm{R}_{3}} \cdot \mathrm{V}_{\text {in }}=\left(\mathrm{Z}_{\mathrm{HP}}+\mathscr{R}\right) \cdot \mathbf{I}
$$

Transconductance ratio

$$
\frac{\mathrm{I}}{\mathbf{V}_{\text {in }}}=\frac{\left(\mathrm{RB}_{\mathrm{B}}+\mathrm{Z}_{2}+\mathrm{R}_{3}\right)}{\mathrm{R}_{\mathrm{B}} \cdot \mathrm{R}_{3}} \quad \mathrm{Z}_{2}=\frac{p^{2} \cdot \mathrm{R}_{2}+\mathrm{R}_{2} / \mathrm{L}_{2} \cdot \mathrm{C}_{2}}{p^{2}+\frac{\mathrm{R}_{2}}{\mathrm{~L}_{2}} \cdot p+1 / \mathrm{L}_{2} \cdot \mathrm{C}_{2}}
$$



$\omega_{0}=\frac{1}{\sqrt{\mathrm{L}_{2} \cdot \mathrm{C}_{2}}}$

$$
\mathbf{Q}_{\mathrm{Z} 2}=\frac{1}{\mathrm{R}_{2}} \cdot \sqrt{\frac{\mathrm{L}_{2}}{\mathrm{C}_{2}}}
$$

\section{Non inverting convertor fitted with resonance compensation within the feedback loop}

Fig. 15: Generic simple scheme allowing to reject the mechanical resonance

For the purpose of basic experiments integrated power amplifiers can be tested (TI ${ }^{\circledR}$ OPA 549 for instance). As regards Fig.15, the transconductance ratio characterizing the converter that feeds the transducer is defined with:

$$
\frac{I}{V_{\text {in }}}=\frac{1}{\mathrm{R}_{\mathrm{B}}} \cdot\left(1+\left(\mathrm{Z}_{2}+\mathrm{R}_{\mathrm{B}}\right) / \mathrm{R}_{3}\right)
$$

Now, the nominal parameters (Table III) of the Morel ${ }^{\circledR}$ EM 428 reference transducer can be considered so as to adjust the components values. Then, resulting behaviours regarding impedances (network and transducer) together with the transconductance ratio as regard amplitude and phase shift curves are depicted in Fig. 16.
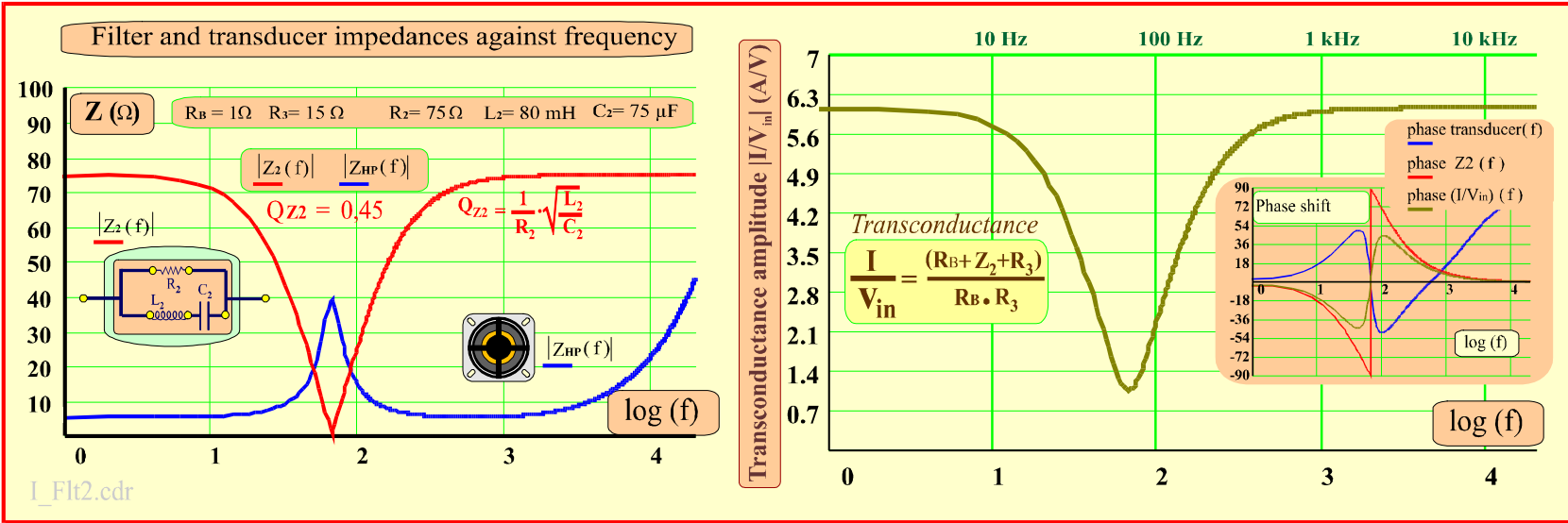

Fig. 16: Respective behaviours of the reference transducer and filtering network

Considering such a basic design, one has to adjust $\mathbf{R}_{2}>>\mathbf{R}_{\mathbf{B}}$ since the $\mathbf{R}_{2}$ value acts on the whole spectral behaviour aside from the resonance regime. Moreover, as regards the stability of the amplifier, $R_{B}$ has to be kept with a quite low value with $\mathbf{R}_{\mathbf{B}}=\mathbf{1} \boldsymbol{\Omega}$ in the given example. As regards Fig.16, a symmetric behaviour can be observed with regard to the transducer and the filtering network. Component values are chosen so as to get an electrical Q close to 0.45 , allowing then to compensate precisely for the transducer behaviour.

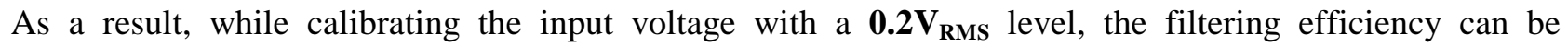
compared with two other cases as depicted in Fig. 17 illustrating the acceleration of the diaphragm against 
frequency. Indeed the behaviour of a simple unfiltered design supplying a unity current is plotted in black, while the natural filtering characterizing a voltage drive $\left(1 \mathrm{~V}_{\mathbf{R M S}}\right)$ is plotted in brown. As is shown by the red curve representing the behaviour of the filtering design, the system operates properly. As a matter of fact any further filtering function (at high frequencies) can be easily compounded to such a system with a classical feedforward scheme.

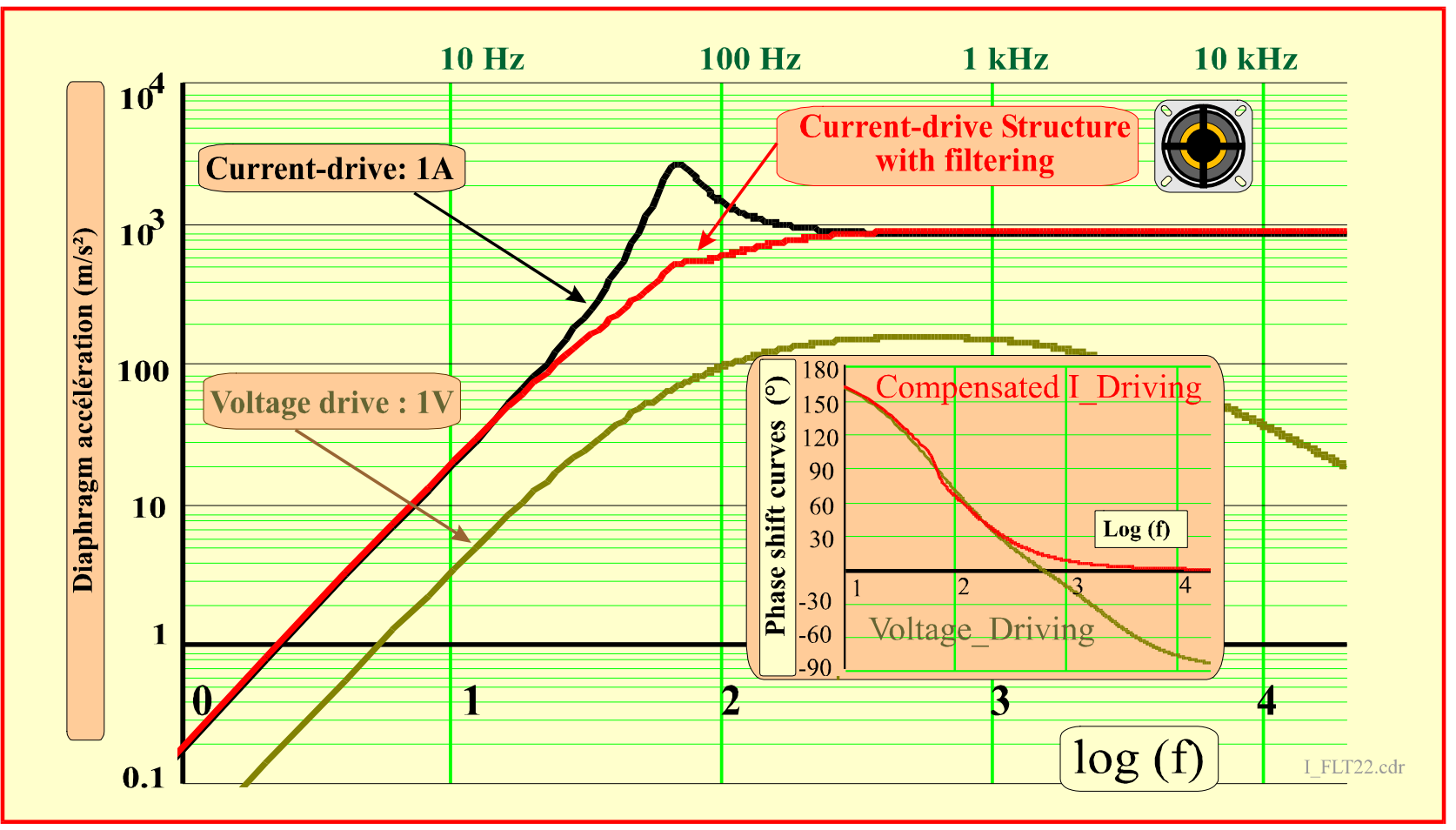

Fig. 17: Compared behaviours with fundamental schemes (respectively unfiltered I-drive and V-drive naturally filtered with the motional impedance of the Morel $^{\circledR}$ EM 428)

However, any industrial project should consider operational schemes out of such a mere theoretical stance. Indeed, due to its size (and cost) the abovementioned inductance $\mathrm{L}_{2}(80 \mathrm{mH})$ could not really be considered with an air-cored copper device, but would require either a ferrite coil structure or a virtual implantation. In this way, with the latter, temperature drift self-compensation solutions are under experiment in the laboratory together with more sophisticated filtering schemes.

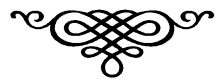


Figures captions

Fig. 1: Natural rejection of nonlinear components due to Eq.2 with an ideal current-drive policy Fig. 2: Static changes measured for the force factor against displacement (Klippel ${ }^{\circledR}$ testing bench) Fig. 3: Simulink ${ }^{\circledR}$ nonlinear numerical evolutive model for a current driven loudspeaker

Fig. 4: Behaviour of the first six harmonic lines according to both analytic and Simulink ${ }^{\circledR}$ approaches Fig. 5: Assessment of the solenoid effect

Fig. 6: Behaviour of the first five harmonic components regarding nonlinear stiffness (with $100 \mathrm{~mA}$ )

Fig. 7: Behaviour of the first five harmonic lines regarding nonlinear stiffness (with $250 \mathrm{~mA}$ )

Fig. 8: Comparison between the relative effects of the second harmonic distortion lines

Fig. 9: Influence of the static pressure on the drag force part of the $f_{\mathrm{m}}$ coefficient

Fig. 10: Influence of the drag force through the third and fifth components $(P=2 \mathrm{bar}, I=0.1 \mathrm{~A})$

Fig. 11: Influence of the drag force through components 3 and 5 , for a 2 bar static pressure (0.25A)

Fig. 12: Real behaviour of each harmonic component displayed according to their own frequency in the case of a nonlinear force factor and a $100 \mathrm{~mA}$ driving current

Fig. 13: Behaviour of each harmonic component displayed according to its own frequency in the case of a nonlinear stiffness parameter and a $100 \mathrm{~mA}$ driving current

Fig. 14: Calculated behaviour of the harmonic components displayed according to their own frequency in the case of an evened nonlinear force factor and a $100 \mathrm{~mA}$ driving current

Fig. 15: Generic simple scheme allowing to reject the mechanical resonance

Fig. 16: Respective behaviours of the reference transducer and filtering network

Fig. 17: Compared behaviours with fundamental schemes (respectively unfiltered I-drive and V-drive naturally filtered with the motional impedance of the Morel $^{\circledR}$ EM 428)

Tables captions

Table I: Coefficients values relative to the first fifth powers of the displacement $X$

Table II: Force factor coefficients entailing the investigated nonlinear behaviour of the transducer

Table III: Theoretical and measured nominal parameters of the EM 428 reference transducer

Table IV: Acceleration reference values associated to the fundamental (current $100 \mathrm{~mA}$ )

Table V : Inductance nonlinear coefficient values

Table VI: Nonlinear coefficient values for the suspension stiffness

Table VII: Level values of the fundamental line with a $100 \mathrm{~mA}$ current driving



